\title{
Infection Prevention and Control in Residential Facilities for Pediatric Patients and Their Families
}

\author{
Judith A. Guzman-Cottrill, DO; ${ }^{1}$ Karen A. Ravin, MD; ${ }^{2, a}$ Kristina A. Bryant, MD; ${ }^{3}$ \\ Danielle M. Zerr, MD; ${ }^{4}$ Larry Kociolek, MD; Jane D. Siegel, $\mathrm{MD}^{6}$
}

\section{EXECUTIVE SUMMARY}

\section{Scope}

The Society for Healthcare Epidemiology of America (SHEA) guideline "Infection Prevention and Control in Residential Facilities for Pediatric Patients and Their Families" is the first infection prevention and control (IPC) guideline to address preventing transmission of infectious agents in "home away from home" residential settings, of which the Ronald McDonald Houses (RMHs) serve as a prototype. These types of facilities provide support services, including overnight lodging, for ill and injured children and their families. Food preparation occurs in common areas, and cleaning of rooms or apartments is performed by the occupants during their stay and before departure. Pediatric patients are frequent guests of the family-centered facilities while receiving or recovering from specialized medical therapy. Examples of highrisk populations served in these facilities include families of patients with cancer, recipients of stem cell or solid organ transplants, surgical and/or very-low-birthweight infants who receive care in neonatal intensive care units (NICUs), those with cystic fibrosis, and women with high-risk pregnancies awaiting delivery in a nearby medical center. Such facilities are located worldwide and vary in their physical structure and the predominant population served.

Development of this guideline began after the presentation of IPC questions that 2 of the authors (J.A.G.-C., K.A.R.) had received from the local RMHs to the SHEA Pediatric Leadership Council in October 2010. There are risks of transmission that may be reduced by following practical IPC procedures, but existing IPC guidelines for hospitals and long-term care facilities are too stringent for a residential family-centered facility. Following discussions with executive leaders of Ronald McDonald House Charities, Inc. (RMHC), a guideline writing group was formed, and a unique collab- orative effort began with a needs assessment ${ }^{1}$ and establishment of a memorandum of understanding between SHEA and RMHC. While RMHC was involved in establishing this effort, the intention has always been to create a guideline that could be used by any such residential facility. If a familycentered residential facility is located within a medical facility, then the facility's IPC-related policies and procedures will supersede the recommendations contained in this guideline. In most situations, a hospital policy or procedure will contain more detailed and structured instructions than this document provides. This document will not include specific information on food safety, as this is addressed in another RMHC document.

This document differs from other SHEA-endorsed guidelines: (1) The primary audience of this guideline is not healthcare personnel but rather lay staff members and volunteers who are educating and monitoring visitors for illness or exposures in a program providing accommodation to ill and injured children and their families. Thus, the terminology used throughout the document is easily understood by individuals of varying educational backgrounds. (2) Peerreviewed healthcare epidemiology literature related to this specific pediatric setting is sparse. Recommendations were developed by adapting currently available infection prevention and control evidence to this special setting. Where published evidence does not define the best practices, this guideline provides practical recommendations. Ultimately, management decisions must be individualized for the specific circumstance, and staff members are encouraged to rely on local expertise for complicated problems. Many recommendations for infection prevention and control in day care settings and ambulatory clinics are applicable to RMHs and like facilities. Literature searches were performed by the writing group and recommendations from guidelines published by the Centers for Disease Control and Prevention (CDC),

Affiliations: 1. Department of Pediatrics, Oregon Health and Science University, Portland, Oregon; 2. Department of Pediatrics, Geisinger Medical Center, Danville, Pennsylvania; 3. Department of Pediatrics, University of Louisville, Louisville, Kentucky; 4. Department of Pediatrics, University of Washington, Seattle, Washington; 5. Department of Pediatrics, Northwestern University Feinberg School of Medicine, Chicago, Illinois; 6. Department of Pediatrics, University of Texas Southwestern Medical Center, Dallas, Texas; a. Present affiliation: Department of Pediatrics, Nemours/Alfred I. duPont Hospital for Children, Wilmington, Delaware.

Received July 4, 2013; accepted July 5, 2013; electronically published September 4, 2013.

(C) 2013 by The Society for Healthcare Epidemiology of America. All rights reserved. 0899-823X/2013/3410-0001\$15.00. DOI: 10.1086/673141 
SHEA, the American Academy of Pediatrics (AAP; Red Book 2012), and the World Health Organization (WHO) when applicable to the residential setting. Recommendations were not assigned a "grade" based on quality of evidence and strength of recommendation because of the sparse evidence to support practices in this setting.

\section{Structure}

The guideline contains several sections that contain background information to enhance the user's understanding of the topics. Recommended practices for the staff of the facility are included immediately following the informational discussions. Sections included in the document are: (1) introduction; (2) background; (3) core principles of infection prevention and control; (4) description of special populations often using the services of residential facilities and their vulnerabilities; (5) alphabetical list of 21 conditions caused by infectious agents or specific infectious agents; (6) background literature cited; (7) Appendix A, which contains 2 documents that may be used by staff; ( 8 ) Appendix B, which contains information concerning vaccines used in children and adults to prevent infectious diseases; and (9) Appendix C, which contains a summary table of infections with specific recommendations for $(a)$ exposed healthy guests, $(b)$ guests with specified infections, $(c)$ restrictions needed within the facility, (d) availability of special educational handouts for family members, and $(e)$ miscellaneous comments for each condition.

Three family education guides focusing on hand hygiene, respiratory etiquette, and safe handling of blood and body fluids were also created as part of this guideline but are not contained in this document. These guides are tools to educate families about how to help with minimizing the risk of pathogen transmission. These guides can be found at http:// www.shea-online.org/Patients.aspx.

\section{Core Principles of Infection Prevention and Control}

The core principles of infection prevention and control that form the foundation for recommended practices are (1) Standard Precautions; (2) management of animals that are utilized for animal-assisted therapy, service animals, or "house pets"; (3) protection of highly immune-compromised patients from exposure to mold spores; (4) health screening of house guests and visitors; (5) management of ill staff members and volunteers; (6) safe handling and storage of breast milk and maintenance of breast milk pumps; and (7) understanding what special populations are especially vulnerable to infection and the associated adverse effects. An understanding of these principles and the associated recommendations will assist staff members, volunteers, and families in making safe decisions when faced with a situation that holds a risk of transmission of infectious agents to others.

Standard Precautions are a set of practices aimed at preventing transmission of infectious agents and are based on the principle that all blood, body fluids (eg, material coughed up and saliva), secretions, excretions (eg, urine, stool, and wound drainage but not sweat), nonintact skin, and mucous membranes may contain transmissible infectious agents and, therefore, these body fluids must be contained as much as possible. The various components of Standard Precautions and major recommendations in this document are as follows:

1. Hand hygiene: Perform hand hygiene before preparing food or eating, before administering medication to a patient, and after changing diapers, toileting or assisting others in toileting, or soiling with body secretions or soil.

2. Glove use: Use gloves when contact with blood or body fluids is anticipated, always perform hand hygiene after glove removal, and never wash and/or reuse the same gloves more than once.

3. Respiratory hygiene/cough etiquette: Contain respiratory secretions by covering coughs and sneezes with a tissue, promptly disposing of soiled tissues, and performing hand hygiene afterward. Maintain a distance of 3-6 feet (1-2 meters) from anyone who is coughing or sneezing.

4. Blood and body fluid precautions: Blood and body fluids may contain transmissible infectious agents (eg, hepatitis viruses, human immunodeficiency virus).

5. Safe injection practices: Prevent needlesticks and exposure to blood by handling all needles used for injection of medications carefully, not recapping used needles, using needles only once, and disposing used needles separately from all other trash in a rigid, puncture-resistant container.

6. Laundry management: Do not shake linens and clothing soiled with blood, vomitus, stool, and so on; keep separate in a plastic bag and wash separately in soap and hot water in order to prevent transmission of infectious agents.

7. Cleaning and disinfection of environmental surfaces: Define and follow routine housekeeping procedures in each house. All items that require disinfection must first be cleaned with a detergent before using a disinfectant. Toileting and diapering areas must always be separate from food preparation areas. Surfaces and items in common areas and playroom should be cleaned and disinfected frequently, and toys that are smooth and scrubbable are preferred to facilitate cleaning.

Notable among the core principles of infection prevention and control is the health screening of house guests and visitors for exposure to infectious diseases and the presence of signs or symptoms of active infectious diseases, especially during seasons when certain infectious diseases are prevalent in the community (eg, influenza, respiratory syncytial virus [RSV], and rotavirus), and management of ill staff members and volunteers. Screening tools are provided in Appendix A.

\section{Specific Diseases and Pathogens}

The purpose of this section is to provide guidance for straightforward problems (eg, bed bugs, head lice, conjunctivitis, and 
diarrhea) and to provide education on recognition of the more complicated conditions (eg, chickenpox, whooping cough, measles, and tuberculosis exposures; infections and colonization with multidrug-resistant organisms; and prevention of influenza). Guidance is provided for the staff of houses for use of local resources (eg, infection prevention and control in referring hospitals, local and state public health departments). While some conditions may be managed by the staff independently, others may require consultation with the referring hospital medical staff.

We recognize that it is not the primary responsibility of the staff of these facilities to assure appropriate immunization status of its staff, volunteers, and guests. However, we encourage these types of facilities to join the many corporations that have found that providing information concerning needed vaccines, especially influenza vaccine, is beneficial to maintaining a healthy environment with reduced absenteeism.

\section{Summary}

This guideline responds to the evolving changes in the delivery of health care to children worldwide, which frequently includes long-distance travel for specialized medical treatment. Family-centered residential facilities located close to pediatric medical centers serve as bridges to returning home. The primary objective is to improve the health of the dedicated staff members and volunteers and of the vulnerable patients and their families who utilize these family-centered facilities that were developed to meet growing needs and improve the quality of life for children worldwide.

\section{INTRODUCTION}

\section{Background}

Throughout the United States and other countries worldwide, families travel long distances to access specialized pediatric care. Thus, RMH programs and similar facilities have become integral components of pediatric family-centered care. In this guideline, we refer to the $\mathrm{RMH}$ as the prototype for such facilities, but it is our intention to develop recommendations that will be applicable to all facilities of this type. These types of facilities provide support services, including overnight lodging, for ill and injured children and their families. Pediatric patients are also frequent guests of the family-centered facilities, while receiving or recovering from specialized medical therapy. Examples include children traveling several hours for a specialty clinic appointment, immune-compromised children recovering from hematopoietic stem cell or solid organ transplantation, children receiving intensive outpatient therapy, or premature infants of a multigestational birth recently discharged from a NICU whose siblings remain hospitalized. Some facilities may also include women with highrisk pregnancies who must be close to the specialty delivery hospital if labor begins early. The patient population may be varied in one facility, while another may serve nearly exclusively families of NICU patients. In 2011, SHEA and RMHC established a formal collaboration to develop an IPC guideline, as both organizations agreed that RMH staff and other organizations operating similar programs would benefit from a standardized approach.

$\mathrm{RMH}$ programs, the cornerstone program of RMHC, provide a "home away from home" for families while their children receive medical care. In 1974, the first RMH opened in Philadelphia, Pennsylvania. ${ }^{2}$ As of January 2013, 323 RMHs exist across 31 countries; 176 of these are in the United States. More than 6,000 families stay at a RMH per night worldwide; the facilities vary greatly in size, accommodating $4-400$ persons per night. Most RMHs are freestanding structures. However, some RMH programs exist within a children's hospital. RMHs provide housing, meals, laundry facilities, and family activities at little or no cost to occupants. Lengths of stay range from 1 night to several months, depending on the child's medical needs. There is no maximum length of stay. The minimum criterion for a patient and/or family to stay includes receiving daily outpatient care or treatment as an inpatient; families are routinely reevaluated to determine their eligibility for continuing stay.

RMHs differ substantially from hospitals and long-term care facilities. RMH staff do not provide medical services, there are no facility requirements to minimize or measure environmental exposures (eg, dust and mold), and standardized policies for environmental disinfection do not exist. While local RMHC Chapters employ staff or service providers to maintain housekeeping and cleanliness standards, RMH also relies on guests and volunteers for routine cleaning and disinfection of common areas. When a family "checks out" of a sleeping room, it is initially cleaned and disinfected by the departing family or a volunteer before the next family "checks in." Chapter staff, volunteers, or a housekeeping service follow with room checks to confirm standards of cleanliness have been met.

In all RMHs with overnight accommodations, meals are prepared and consumed in a common kitchen and dining room, and guests share in the cleanup duties after meals. Kitchens are open 24 hours a day, as a family's meal schedule might be dictated by the child's around-the-clock medical care and changing health status. Each family has a designated area to store their own perishable and nonperishable foods. RMHC staff and volunteers review the refrigerator and freezer contents at least once weekly to discard spoiled food. Some houses have apartments dedicated to high-risk transplant patients that include separate food preparation and dining areas.

The annual incidence of infections acquired in the RMH setting is unknown. Similarly, it is unknown how RMH guests (including patients living at a $\mathrm{RMH}$ ) influence the affiliated hospital's epidemiology. RMH guests are at risk of exposure to infectious pathogens in common areas, such as family lounges and community kitchens. Many pediatric hospital epidemiologists can anecdotally recall at least 1 hospital outbreak investigation that included their local RMH. 
However, this has never been formally reviewed, and outbreaks related to stay in a residential facility are not easily identified in the medical literature. In fact, literature review revealed only 1 published report (a hospital varicella outbreak involving a $\mathrm{RMH}){ }^{3}$ Despite this direct relationship with healthcare facilities, no standardized RMH IPC guideline exists.

Each RMH is owned and operated by a local Chapter and governed by a locally organized board of directors. However, all Chapters are official licensees of McDonald's Corporation, which is located in Oak Brook, Illinois. This governance structure allows for local flexibility within a framework of policies and practices among individual RMHC Chapters, including the management of IPC issues. Most sites have locally written IPC guidelines, and consultation resources vary, ${ }^{1}$ increasing the potential for inconsistency.

Hospital infection prevention and control guidelines do not apply to most RMH settings, since such guidelines are developed to protect patients who are vulnerable when hospitalized, undergoing a variety of procedures, and exposed to medical devices. It is both unnecessary and unrealistic to expect a residential facility to adhere to strict hospital guidelines. Specifically, hospital infection prevention and control policies do not align with the RMHC mission of serving families during a time of crisis in a community setting through its $\mathrm{RMH}$ program. It was recognized that development of a guideline would require a strategy appropriate for the spectrum of RMH programs, as they differ in size, amenities, patient populations, and location (freestanding versus a program within a hospital).

The recommendations in this guideline address general and specific topics of infection prevention and control that may be applied to various nonhealthcare settings. The discussions and recommendations will include the concepts of Standard Precautions, screening visitors for exposures to infectious diseases, excluding staff members and visitors with transmissible infections, prevention of outbreaks, and optimizing the health of local RMHC staff members and volunteers through education.

This document differs from other SHEA-endorsed guidelines. First, the primary audience of this guideline is not healthcare personnel; instead, the guideline is a reference for staff members and volunteers who are educating and monitoring visitors for illness or exposures in a program providing accommodation to ill and injured children and their families. Thus, the terminology used throughout the document was chosen for that target audience. Second, healthcare epidemiology literature related to this specific pediatric setting is sparse. Recommendations were developed on the basis of adaptation of currently available evidence to this special setting. Where published evidence does not define the best practices, our guideline provides practical recommendations. Ultimately, management decisions must be individualized for the specific circumstance. Many recommendations for infec- tion prevention and control in day care settings and ambulatory clinics are applicable to RMHs and like facilities.

\section{Demography and Definitions}

The number of children in the United States is rising. The 2010 census reported 74.2 million children living in the United States, and this population is projected to increase to 87.8 million by $2030 .{ }^{4}$ Concurrently, the number of children and youth in the United States with chronic health conditions has increased in the past 4 decades, ${ }^{5}$ as survival rates have improved for life-threatening pediatric diseases such as prematurity, cancer, and cystic fibrosis (CF) ${ }^{6-8}$ As the need for specialized pediatric care increases, the demand for $\mathrm{RMH}$ services also increases; it is projected that more than 350 RMHs will be operating by the end of 2015 (J. Burton at RMHC, personal communication, 2013).

A RMH is a facility operated by a local RMHC Chapter that provides overnight accommodations to families while their child receives medical care. It may be freestanding or housed within a children's hospital. A Ronald McDonald Family Room (RMFR) is a program within the hospital operated by a local RMHC Chapter that provides day and, in many programs, overnight services for families while their children receive medical care. An example of a RMFR is an area near a pediatric day hospital where children receive chemotherapy infusions. A RMH guest is a patient or family member who utilizes RMH services (including overnight stay). A RMH visitor is an individual who enters a House but does not utilize their services, such as someone attending a RMH tour or visiting a RMH guest. A RMH staff member is a person employed by a local RMHC Chapter, and a RMH volunteer is someone who contributes unpaid support to RMH program daily operations. A healthcare provider is defined as an individual permitted by law and by the healthcare facility to provide medical care without direction or supervision within the scope of the individual's license and consistent with individually granted clinical privileges (eg, physician, nurse practitioner, or physician assistant).

\section{IPC Needs Assessment}

A needs assessment was a critical first step in guideline development to aid in determining the topics and recommendations included in this document. This assessment sought to identify the populations served and the most frequent IPC situations encountered by RMH staff and to understand the methods and resources used to manage IPC situations as they arise. The survey findings are summarized in detail elsewhere. ${ }^{3}$

Focus group and site visits. Several authors attended the RMHC International Conference in Chicago (August 2011) to learn more about the diversity of the RMHs and their IPC needs. The authors coordinated a stakeholder's group meeting with board members and managers of RMHs both within and outside of the United States to better understand the IPC challenges encountered. In January 2012, 2 authors toured 3 
$\mathrm{RMH}$ programs in Houston, Texas, with a $\mathrm{RMH}$ organizational leader and program managers. During these 2 meetings, greater insight was gained regarding the IPC challenges, the variety of physical structures of RMHs, and the types of questions staff members have about management of patients and families with an infectious condition or a history of exposure to others with infections.

\section{Scope of the Guideline}

The scope of this guideline is specifically for family-centered residential facilities that provide accommodation and other services to families with ill and injured children. However, these facilities may vary in the populations served, healthcare services provided (RMH does not provide healthcare services), human and fiscal resources, and governance structure. In such situations, the recommendations should be adapted to meet these specific conditions.

If a family-centered residential facility is located within a medical facility, then the facility's IPC-related policies and procedures will supersede the recommendations contained in this guideline. In most situations, a hospital policy or procedure will contain more detailed and structured instructions than this document provides. This document will not include specific information on food safety, as this is addressed in another RMHC document.

\section{CORE PRINCIPLES OF INFECTION} PREVENTION AND CONTROL

\section{Background}

Preventing transmission of infectious agents among patients, families, and healthcare personnel is a challenge in all settings where health care is delivered. There is considerable research informing the recommendations made for preventing transmission of infectious agents in healthcare facilities in guidelines and position papers published by the Healthcare Infection Control Practices Advisory Committee/Centers for Disease Control and Prevention (HICPAC/CDC), ${ }^{9}$ SHEA, ${ }^{10}$ and the Infectious Diseases Society of America (IDSA). ${ }^{10}$ There has been little research and few published guidelines for ambulatory settings. Similarly, infection transmission within family-centered facilities has not been evaluated. Special ambulatory settings for which infection prevention and control guidelines do exist include hemodialysis centers ${ }^{11}$ and CF clinics. ${ }^{12}$ In 2011, guidelines for general outpatient clinics ${ }^{13}$ and oncology clinics ${ }^{14}$ were developed by the CDC that describe the minimum expectations for safe care in outpatient settings. There is no research to inform recommendations to prevent transmission of infectious agents in family-centered facilities that serve as a "home away from home."

Although RMHs are not healthcare facilities, they are "residences" with potential for exposure to infectious diseases. Patients with medical conditions that make them particularly vulnerable to infection live in and share common facilities with many other children and their families. Such communal living can provide opportunities for transmission of infectious agents if caution is not taken. By understanding the principles of prevention of infection transmission, all individuals who live and work in such facilities can reduce the risk of infection for children and families whom they serve.

\section{Standard Precautions}

Standard Precautions are a set of practices aimed at preventing transmission of infectious agents and are based on the principle that all blood, body fluids (eg, material coughed up and saliva), secretions, excretions (eg, urine, stool, and wound drainage but not sweat), nonintact skin, and mucous membranes may contain transmissible infectious agents. Therefore, containing these fluids will reduce the risk of transmission of infectious agents. Employees, volunteers, patients, family members, and visitors must all partner in preventing transmission of infections in healthcare settings. Recommendations for Standard Precautions are based on strong evidence from healthcare settings that has been summarized and referenced in several guidelines published by HICPAC/CDC, the IDSA, ${ }^{15}$ and the World Health Organization. ${ }^{16}$

Elements of Standard Precautions that can be applied in RMHs or similar facilities are as follows:

1. Hand hygiene: This is a general term that applies to any one of the following: (a) hand washing with plain (nonantimicrobial-containing) soap and water, $(b)$ hand washing with soap containing an antiseptic agent, or $(c)$ cleaning hands with a waterless alcohol-based hand rub containing at least $60 \%$ alcohol. Performing hand hygiene at the appropriate times is a critical step one can take to prevent transmission of infectious agents and has been shown to be effective in both healthcare and nonhealthcare settings, such as day care centers, dormitories, and schools. ${ }^{17-20}$ Placement of alcohol-based hand rub dispensers at the entrance to facilities; in hallways; in guest rooms; in areas where food is prepared, served, and consumed; and in areas where there may be contact with house pets will facilitate performance of hand hygiene by all guests and visitors. Hand washing with soap and water is preferred after handling soiled diapers or items contaminated with stool and whenever hands are visibly soiled.

2. Glove use: Gloves should be used to provide additional protection when individuals are likely to come in contact with body secretions, excretions, nonintact skin, and mucous membranes. It is important to understand that gloves are not a replacement for hand hygiene. Gloves reduce the level of contamination on hands but they do not eliminate it because there may be tiny holes that are not visually obvious. Furthermore, hand hygiene is recommended after removing gloves since hands can become contaminated in the process of removing gloves. Also, gloves are meant to be used only a single time and should never be washed and reused because infectious agents cannot be washed 
off of gloves. In healthcare settings, hands are cleaned both before and after glove use. In a home setting this is ideal, but washing hands immediately after glove removal is a must.

3. Respiratory hygiene/cough etiquette: Since it is not always known what respiratory agent a person may have when there are signs of respiratory illness, including cough, congestion, rhinorrhea (runny nose), sneezing, or increased production of respiratory secretions, all respiratory secretions are considered potentially infectious. Therefore, it is recommended to cover the mouth and nose with a tissue when coughing or sneezing, immediately dispose of the tissue in a waste receptacle, and perform hand hygiene when finished. If tissues are not readily available, then sneezing or coughing into one's sleeve is safer than sneezing or coughing into the air. However, caution is advised if it is likely that an infant or child will be cradled or held in one's arms and come into contact with soiled sleeves. Since most viruses and bacteria travel a distance of 3-6 feet (1-2 meters), it is advised that vulnerable patients remain at least 3-6 feet (1-2 meters) away from individuals who are coughing or sneezing. Medical care providers will advise patients with weakened immune systems to avoid crowded places and/or to wear masks when they are in public areas for additional protection against respiratory tract infections. These "surgical masks," sometimes referred to as "isolation masks," cover the mouth and nose but do not fit tightly on the face. If someone is coughing near a vulnerable child, move the child away from that person or ask the coughing person to move away from the child and/or to please cover his or her cough for the protection of others. See Appendix B ("Vaccines") for additional steps that can be taken to reduce the risk of acquiring certain vaccine-preventable respiratory tract infections.

4. Blood and body fluid precautions: Some infectious agents can be acquired from exposure to blood and body fluids. Staff, volunteers, and guests should always assume that any blood or body fluid may be infectious.

a. Advise families to not share personal items such as toothbrushes or razors with others, even within their own family.

b. Restrict entrance of an individual with open skin lesions that cannot be covered or other conditions that might allow contact with their body fluids.

c. If an infected person or their family member has behaviors (eg, biting) that might put others at risk of contact with their blood or body fluids, specific restrictions may be required and should be determined on an individual basis.

d. See section 7 ("Cleaning and disinfection of environmental surfaces") below for guidance on cleaning surfaces contaminated with blood.

5. Safe injection practices: Caregivers may need to use needles to administer medications either through a central venous catheter (often called a central line or PICC line) or by direct injection (eg, insulin). Because needles are contaminated with a patient's blood after injection, it is possible for a caregiver or program staff member to acquire a bloodborne infection if he/she sustains an accidental needlestick with a used needle. Hepatitis $B$ and $C$ viruses and human immunodeficiency virus (HIV) can be transmitted via needlestick injuries. Hospital personnel should instruct families how to safely handle needles at the time when methods of injectable medication administration are taught. All needles used for medication administration must be handled carefully. Used needles and syringes must never be recapped or used more than once. Single-dose vials of medications are always preferred over multidose medication vials to reduce the risk of contamination. Medication vials, insulin pens, and fingerstick devices for blood sugar monitoring must be used for only a single person. These medical supplies and devices should be stored in the guest's private room at all times. Needles must be disposed of separately from all other trash in a rigid, puncture-resistant container. Housekeeping staff and volunteers should exercise caution when cleaning linens and clearing rooms in the event that needles have not been disposed of appropriately. Additional information about safe injection practices may be found on the CDC website (http://www.cdc.gov/injectionsafety/lanonly.html).

6. Laundry: Linens or clothing that become soiled with blood, stool, or vomitus should be removed as soon as possible in a manner that prevents transfer of infectious agents to others or to the environment. In addition, the following recommendations will further prevent the spread of infectious agents from contaminated linens and clothing:

a. Do not shake soiled linens or clothing.

b. Soiled linens and clothing should be placed in a plastic bag to completely contain fluids.

c. Keep soiled linens and clothing separate from other laundry. Wash soiled linens or clothing in hot water with detergent as soon as possible.

7. Cleaning and disinfection of environmental surfaces: Microorganisms can be spread by contact with an infected person (direct spread) or by touching an object or a surface contaminated with infectious secretions or body fluids (indirect spread). ${ }^{9}$ Many bacteria and viruses can survive for prolonged periods of time on environmental surfaces. ${ }^{21}$ For example, influenza virus can survive on hard surfaces such as stainless steel and plastic for $24-48$ hours. ${ }^{22}$ Cleaning and disinfecting objects and surfaces can help prevent the spread of infection in family-centered residential facilities. Cleaning involves removal of dirt and surface contamination, usually by scrubbing with a detergent and then rinsing with water. Disinfection destroys or inactivates most pathogens (with the exception of spores) on objects or surfaces and is especially important for food preparation surfaces. Since the action of disinfectants is reduced if 
visible substances (eg, stool and nasal discharge) are not removed first, cleaning is an especially important first step.

a. Follow routine housekeeping procedures (eg, cleaning, wet mopping, dusting, and vacuuming) that are recommended to reduce the spread of infection in facilities such as child care centers and schools. The American Academy of Pediatrics (AAP) offers a reference guide that includes recommendations for routine environmental cleaning and disinfection in these settings. ${ }^{23}$

b. All facilities should have a procedure in place for routine cleaning and disinfection of environmental surfaces in common areas that specifies the following:

a) Who is responsible for cleaning and disinfection.

b) What areas and items are to be cleaned and/or disinfected.

c) Frequency of cleaning and disinfection.

d) Who is responsible for supervising and inspecting procedure.

e) Frequency of inspections.

f) Documentation of procedure completion and compliance.

c. For areas that require disinfection (eg, toilet and diapering areas and food preparation areas), use products registered with the US Environmental Protection Agency as detergent-disinfectants or hospital-grade germicides. A solution containing 1/4 of a cup (approximately 59.1 $\mathrm{mL}$ ) of household bleach in 1 gallon (3.8 liters) of tap water is also appropriate for disinfection unless surfaces are contaminated with blood or other potentially infectious body fluids.

d. Immediately clean spills of blood and other potentially infectious body fluids using disposable towels, wearing disposable gloves. Dispose of blood-contaminated materials in a plastic bag that can be closed with a secure tie. A more concentrated solution of 1 part bleach to 9 parts water should be used to disinfect surfaces contaminated with blood and other body fluids.

e. For floors, rugs, and carpeting contaminated by body fluids: while wearing gloves, immediately blot to remove excess fluid, then spot clean the area with a detergentdisinfectant. Shampooing or steam cleaning may be required.

f. In common areas and playrooms, choose toys that can be easily cleaned and disinfected (avoid stuffed or cloth toys because they are not easily cleaned). Clean and disinfect toys daily or more frequently when toys are contaminated with oral or nasal secretions. Small plastic toys may be cleaned and disinfected in a mechanical dishwasher as long as dishes are not washed at the same time. To reduce the potential for environmental contamination with fecal matter, instruct families to perform diaper changes in a guest's room or the bathroom (or other clearly designated area). Diaper changes should not take place in common areas. g. Place soiled diapers in lidded, plastic-lined designated receptacles remote from food preparation areas. Regularly clean and disinfect diaper-changing tables in communal bathrooms (at minimum once daily or whenever visibly soiled).

h. Never use sinks intended for hand washing or food preparation for rinsing soiled clothing or linens, for cleaning equipment that is used in toileting, or for disposal of cleaning waste water.

\section{Animals}

Animals can be a source of various organisms that cause infections in humans. Thus, family-centered residential facilities should ensure that animals allowed facility entry are healthy. Facilities should be aware of local and federal laws related to service animals. To minimize the risk of animalrelated infections, recommended precautions include the following:

1. Do not allow reptiles or rodents (including mice, hamsters, gerbils, and rats).

2. Fish tanks are acceptable as long as they are appropriately maintained and covered, to prevent aerosolization of water into the surrounding air and to prevent guests from placing their hands in the tanks.

3. Do not allow guests to play with fish tank water.

4. Ensure that service or pet animals are healthy prior to facility entry by requiring written documentation.

5. If service or pet animals are present, perform hand hygiene both before and after touching the animal.

6. Do not allow service and pet animals to lick guests with invasive devices or compromised immune systems.

7. Do not allows guests to handle animal feces or excrement.

8. Notify immune-compromised guests if an animal is present in the house. Request the family to consult the patient's healthcare provider to determine if animal avoidance is recommended.

\section{Protection of Highly Immune-Compromised Patients from Exposure to Mold Spores}

Organisms routinely found in soil, water, construction dust, and decaying organic matter, including fungal organisms such as Aspergillus species that release spores into the air, may cause serious disease of the lungs, sinuses, brain, and other organs in highly immune-compromised patients (eg, those with very low white blood cell counts and stem cell transplant recipients). In hospitals, hematopoietic stem cell (bone marrow) transplant patients are the most immune-compromised patients and are housed in units with specially filtered air handling systems, increased number of air exchanges per hour, and rooms with specialized air flow with respect to other rooms and corridors, called a Protective Environment. Once these patients are well enough to no longer require this protective environment, they may be discharged from the hos- 
pital to home or to a family-centered residential facility. Such facilities are not medical facilities and, thus, are not equipped to provide a Protective Environment for these patients. However, simple measures that might be undertaken in a home to reduce the risk of airborne transmission of fungal organisms could be implemented in these facilities. These include proper installation and maintenance of heating, ventilation, and air conditioning (HVAC) systems and scheduled changes of filters according to manufacturers' recommendations, to prevent dust overload. When activities that increase dispersal of fungal spores from the soil are anticipated, including construction and renovation projects, medical personnel at the affiliated facility should be notified, and guests should be informed. During construction and renovation, highly immune-compromised individuals should consult their healthcare providers about their exposure risks and inquire if alternative housing should be considered.

Additional precautions that could be recommended by the highly immune-compromised child's healthcare team are listed below:

1. Avoid exposure to construction sites or the outdoors on windy days.

2. Wear a special type of mask (N95 respirator) that fits tightly on the face when going outdoors for necessary travel to and from the hospital.

3. Avoid carpeting, because carpet can retain mold spores that may be dispersed into the air during vacuuming or other activities.

4. If carpeting is present, vacuum the area regularly using a high-efficiency particulate air (HEPA)-filtered vacuum when the patient is not present.

5. Avoid the use of humidifiers and dehumidifiers in common areas. If humidifiers or dehumidifiers are used in individual rooms, observe the recommended care practices per manufacturer or as instructed by healthcare staff members.

6. Do not keep potted plants or fresh flowers in the room.

7. Avoid gardening, digging, and spreading mulch or soil.

8. Avoid areas where gardening, digging, and mulching are taking place.

\section{Health Screening of House Guests and Visitors}

All visitors and prospective guests should be systematically screened for illness or exposure to infectious diseases when they arrive at the reception desk or when arrangements for admission are being made. The process should include a standardized list of symptom and exposure questions; a health screening tool is provided (Appendix A) and can be modified to fit the needs of each family-centered facility. Each facility should develop a standardized method to ensure that all staff members are trained to follow the same procedure. If a visitor answers yes to any of the questions, the visit should be res- cheduled for a future date. Similarly, prospective guests who answer yes to any of the questions should arrange for alternative accommodations or should remain in their private room, depending on the specific situation (see "Specific Diseases and Pathogens" for additional guidance). Since hospital social workers are frequently involved in the family screening and referral process, it is important for them to be aware of the screening process details.

Each prospective guest should be asked about his or her varicella (chickenpox) immune status, and this information should be maintained on file until the guest checks out from the facility, always being aware of and taking steps to maintain the confidentiality of this information. Rapid access to this information is beneficial in the event that a facility is involved in a varicella outbreak investigation. Throughout the influenza season (from September to March in the Northern Hemisphere), prospective guests should be asked about their influenza vaccination status. If the family member has not yet received an influenza vaccine, program staff should provide information about the importance of immunization, especially while living in a community setting. Whenever possible, family-centered facilities may assist guests with identifying local facilities that offer influenza vaccines (eg, pharmacies and health department clinics).

Family members of a patient who is diagnosed with an infectious disease should not be automatically excluded from services. Program staff members should refer to "Specific Diseases and Pathogens" for details. Some specific illnesses of epidemiologic significance require a signed medical clearance document, confirming that the family members are not an infectious risk to guests, staff, and volunteers. The document should be completed by a healthcare provider who is familiar with the child's medical condition. Each organization operating a family-centered residential facility should use a standardized document so that all staff can easily identify a properly completed form; a sample medical clearance form is provided (Appendix A) and can be modified to fit the needs of each program. If the family is unable to obtain a signed medical clearance form or if the form is incomplete, then the family should not be referred or allowed entry to the facility.

If a situation arises where these guidelines do not provide a clear recommendation or if the involved medical providers and program staff are uncomfortable with a recommendation stated within these guidelines, it is appropriate for the program manager, involved healthcare provider, and/or other local leaders (such as an affiliated infection prevention and control program or public health department) to reach a final management determination. When there is evidence of ongoing transmission or concern for a possible outbreak, more stringent infection prevention and control measures will likely be recommended by local consultants. 


\section{Staff Member and Volunteer Illness and Vaccination}

Staff members and volunteers who work while ill may provide suboptimal service and may pose an infectious risk to other staff, volunteers, guests, and visitors. All family-centered residential facilities should develop policies and procedures for evaluating and excluding ill staff and volunteers. At a minimum, staff members and volunteers should report symptoms of any potentially contagious infection (eg, respiratory or gastrointestinal tract illnesses, and vaccine-preventable diseases, including chickenpox, measles, and mumps) to their supervisor. Clinical evaluation by a healthcare provider may be necessary to determine if work exclusion is recommended.

Ideally, all program staff members and volunteers should routinely consult with their healthcare providers to verify their immunization status and obtain the recommended vaccines. By ensuring staff members and volunteers are up to date on recommended vaccines, the risk of exposure of vulnerable patients and their families to vaccine-preventable illnesses such as influenza, pertussis (whooping cough), measles, mumps, and varicella (chickenpox) will be reduced. See Appendix B ("Vaccines") for further details about adult immunizations.

\section{Breast Milk Storage and Maintenance of Breast Pumps}

Human milk is the preferred feeding for all infants, and the AAP recommends exclusive breastfeeding for all infants for the first 6 months of life. ${ }^{24}$ Mothers of hospitalized infants or mothers who must be separated from their infants because of the hospitalization of an older child may need to express and store breast milk while staying as a guest at a familycentered residential facility. Human milk is not sterile, and proper storage and handling is needed to reduce the risk of contamination and growth of microbes that could cause illness. Proper storage and handling of breast milk is an important component of a facility's food safety program.

Expressed breast milk should be stored in glass or foodgrade plastic containers with tight-fitting lids. Alternatively, it may be stored in plastic bags designed specifically for human milk storage. Each container should be clearly labeled with the infant's and mother's full names and the date and time the milk was expressed. Breast milk should be stored so that guests have access only to milk that belongs to their own infants. It must be kept in a refrigerator in a guest's room or in a separate, clearly labeled, and preferably locked container in the communal refrigerator. Freshly expressed breast milk may be refrigerated safely at $4^{\circ} \mathrm{C}\left(39.2^{\circ} \mathrm{F}\right)$ for up to 96 hours. Milk may be stored in the freezer compartment of the refrigerator for 3 months. Thawed breast milk must be kept refrigerated and used within 24 hours.

Inadvertent administration of expressed breast milk to the wrong infant has occurred in healthcare and day care settings and could theoretically result in exposure to infectious agents, including HIV, cytomegalovirus, and hepatitis $\mathrm{B} .{ }^{25}$ Therefore, accidental exposure to breast milk that is not from the infant's mother is generally managed in the same manner as accidental exposures to blood. ${ }^{26}$ The child who received the incorrect breast milk should be referred to his or her healthcare provider for further guidance. The mother who supplied the breast milk (donor mother) should be notified that her milk was inadvertently administered to the wrong child. A healthcare provider should discuss the need for HIV testing with the donor mother if she has never been tested before. The $\mathrm{CDC}$ recommends that the donor mother be asked how the milk was expressed and how the milk was handled before being stored at the facility. ${ }^{24}$ This information should be shared with the parents of the exposed infant and his or her healthcare provider.

Parents of the exposed infant can be informed that the risk of HIV transmission is low from expressed breast milk because known HIV-positive women are advised not to breastfeed their infants. Additionally, chemicals present in breast milk and cold temperatures degrade HIV present in breast milk. Transmission of HIV from a single breast milk exposure has not been documented. Although hepatitis B surface antigen has been detected in the breast milk of hepatitis Binfected women, breastfeeding is not thought to significantly increase the infant's risk of infection, particularly when a birth dose of hepatitis $B$ vaccine has been given. The risk of hepatitis B transmission from an inadvertent breast milk exposure is likely quite low.

\section{Special Populations}

In health care, highly vulnerable special populations are identified on the basis of the risk of acquiring infection and the risk of developing more serious disease once infected, compared with otherwise healthy individuals. These special populations are also likely to spend more time (eg, frequent visits and frequent and prolonged hospitalization) in healthcare facilities due to their underlying conditions. Additionally, they may have medical devices (eg, central venous catheters, tracheostomy tubes, and dialysis catheters) that make them even more susceptible to infection. Patients with weakened immune systems from congenital or acquired immune deficiency, chemotherapy, or immunosuppressive medications may not respond to vaccines or develop protective antibodies. Such patients do not receive most live virus vaccines because their immune systems may not be able to control the weakened vaccine virus. For such patients, it is especially important that close contacts be completely vaccinated to prevent exposure to vaccine-preventable diseases.

Families of patients with these special conditions are educated by the healthcare team about the precautions they need to take to reduce the risk of infection. When arrangements are being made for a family to check into a familycentered residential facility, it is helpful to ask if any restrictions have been recommended by the child's medical 
providers. Examples of the most frequently encountered special populations include the following:

1. Neonates, especially prematurely born

2. Immunodeficiencies
a. Congenital
b. Acquired (eg, HIV/AIDS)
c. Asplenia (congenital/acquired)

3. Immunosuppressive therapy

a. Cancer chemotherapy

b. Hematopoietic stem cell transplant (HSCT, also referred to as bone marrow transplant, or BMT)

c. Solid organ transplant (eg, lung, liver, kidney, heart, and small bowel)

d. Rheumatologic diseases (eg, systemic lupus erythematosus [SLE] and juvenile idiopathic arthritis [JIA])

e. Inflammatory bowel disease (eg, Crohn disease and ulcerative colitis)

4. Cystic fibrosis

5. Pregnancy

Neonates. All infants are born with an immature immune system that develops throughout the first few weeks and months of life. The more premature an infant, the more compromised the immune system is at birth. Additionally, prematurely born infants with chronic lung disease or certain anatomic anomalies may be predisposed to both acquiring infection and developing serious complications of infections.

Immunodeficiencies (congenital or acquired). Some children may be born with deficiencies or complete absence of various components of their immune systems; these are referred to as congenital immunodeficiencies. Some deficiencies are so severe that those affected may eventually require a bone marrow or stem cell transplant. Most congenital immune deficiencies result from genetic abnormalities and can affect different components of the immune system.

There are many ways in which immunodeficiency may be acquired after birth, including HIV infection or loss of the spleen due to either disease (eg, sickle cell disease) or trauma.

Immunosuppressive therapy. Treatments for a variety of conditions (eg, cancer, SLE, and inflammatory bowel disease) include potent chemical and biological agents or radiation that suppress the body's immune system, often used to allow the body to accept lifesaving transplants of organs, bone marrow, or stem cells. For each condition, the degree of immunosuppression and vulnerability can be predicted during the patient's stages of treatment. The most vulnerable patients are stem cell transplant patients, usually within the first 100 days following transplant or during all periods when they experience rejection of the transplanted cells (graft-versushost disease). These patients are especially susceptible to disease caused by mold normally found in the air, particularly near construction sites or water leaks that have not been promptly repaired within 72 hours. The healthcare team can provide information about the degree of protection needed.
These patients may be separated from others until their immunity improves.

Cystic fibrosis (CF). Patients with CF are susceptible to many infectious agents and will develop a decline in lung function after infections with common respiratory viruses that may not cause serious disease in others. Compared with other patients, patients with $\mathrm{CF}$ require additional protection to prevent transmission from contaminated respiratory therapy equipment and from respiratory secretions of other patients with CF. Infectious agents such as Burkholderia cepacia complex and Pseudomonas aeruginosa have unique clinical and prognostic significance for individuals with CF. B. cepacia infection has been associated with increased morbidity and mortality. ${ }^{12}$ This unusual pathogen is rarely found in patients who do not have CF, unless they have been exposed to a contaminated medical product. Person-to-person transmission of $B$. cepacia complex has been demonstrated among children and adults with $\mathrm{CF}$ in healthcare settings, during various social contacts (most notably attendance at camps for patients with $C F$ ), and among siblings with $C F{ }^{12}$ There is also an increasing amount of information suggesting similar patient-to-patient transmission of strains of Pseudomonas aeruginosa. Although patients with $\mathrm{CF}$ have traditionally found support by socializing with other patients with $\mathrm{CF}$, the threat of acquiring dangerous bacteria from one another has led to recommendations that patients with CF SHOULD NOT socialize with each other. In residential houses, siblings who live together in the same home may reside and socialize together. However, nonsiblings with CF should not socialize, have meals, or room together. ${ }^{12}$ An updated guideline for infection prevention and control in people with cystic fibrosis is in preparation.

Pregnancy. Pregnancy is not associated with a true immunodeficiency. However, there are certain infectious agents that may affect the fetus adversely if infection occurs during pregnancy. Consistent hand hygiene and avoiding sick contacts, cat litter, and undercooked meat are just some of the recommendations that will help to keep pregnant women healthy. Ideally, pregnant women who are staying in residential facilities will have been counseled by their obstetricians.

\section{SPECIFIC DISEASES AND PATHOGENS}

\section{Bed Bugs}

Background. Bed bug infestations involving homes, hotel rooms, apartments, dormitories, and hospitals have been reported with increasing regularity in the United States over the last 30 years. ${ }^{27}$ Bed bugs (Cimex lectularis) are reddishbrown wingless insects $1-7 \mathrm{~mm}$ in length. During the day, bed bugs hide themselves in the seams of mattresses and bedding, in crevices of box springs and wooden headboards, under carpets, or behind loose wallpaper, emerging at night to feed on the blood of sleeping humans. Clues that suggest an infestation include rust-colored blood spots on mattresses or furniture or a sweet, musty odor. 
Infestations are spread when the insects are carried from place to place on suitcases, furniture, clothing, and other personal items. Moving personal items such as clothing and luggage from an infested room to another room in the facility may spread the infestation. Bed bugs may also travel short distances (ie, room to room or apartment to apartment) on their own, migrating along pipes or ventilation ducts.

Bed bug bites most often result in itchy red papules at the site of the bites that may appear similar to bites caused by mosquitoes and other bugs. However, they are usually larger and on parts of the body exposed during sleeping. Not all people bitten by bed bugs develop a skin reaction because the skin reaction is often an allergic response. Bed bugs have not been proven to transmit infectious disease, but occasionally skin that has been scratched will become secondarily infected with bacteria that normally live on the skin. ${ }^{28}$ Individuals with bed bug bites are not contagious. Complaints of waking with itchy skin lesions that were not present before going to sleep should prompt suspicion of a bed bug infestation. If a bed bug infestation is suspected, follow the recommendations below.

\section{Recommendations}

1. Instruct families to inspect bedding, mattresses, luggage, clothing, and other personal items for the presence of bed bugs.

2. Wash and dry clothing and bedding at hot temperatures to eliminate bed bugs.

3. Seal items that are not amenable to washing and drying in a plastic bag and remove them from the facility.

4. Successful eradication of bed bugs from the environment is best accomplished by professionals who perform a thorough inspection and, if indicated, application of an insecticide. Eradication of bed bugs may require more than 1 treatment, and thus serial room inspections are necessary. If 1 room is found to be infested, inspect all rooms.

5. Adjunctive control measures include (1) vacuuming, (2) reducing clutter where bed bugs could hide, (3) eliminating peeling paint and plaster and caulking cracks and crevices in wall and furniture that could harbor bedbugs, and (4) encasing mattresses and box springs in protective covers.

6. The program manager should notify the affiliated healthcare facility about the discovery of bedbugs so that the relevant inpatient rooms can be assessed for infestation.

\section{Clostridium difficile Diarrhea}

Background. Clostridium difficile (commonly referred to as "C. diff" or "C. difficile") is a bacterium that may be found in the intestines of healthy infants but in only a small percent of otherwise healthy adults. ${ }^{29-31} \mathrm{C}$. difficile is one of the most frequent infections acquired by individuals within the healthcare setting. ${ }^{29}$ When infection does occur, $C$. difficile most often leads to colitis (ie, inflammation of the large intestine), manifested as fever, abdominal pain and/or cramping, and diarrhea with or without blood. ${ }^{31} \mathrm{C}$. difficile colitis occurs most often in hospitalized patients receiving antibiotics, other medications such as chemotherapy, or surgery, although it can also occur in individuals without risk factors. ${ }^{31,32}$

C. difficile has the ability to form hardy spores that are able to survive for extended periods of time on environmental surfaces and on the hands of individuals who come into contact with these spores. ${ }^{9}$ Uninfected individuals can acquire C. difficile from ingestion of spores found in the environment. In healthcare facilities, effective methods to reduce transmission include avoiding unnecessary antibiotic use, placement of patients with $C$. difficile-associated diarrhea on isolation precautions, use of gloves followed by hand washing with soap and water, and thorough cleaning of rooms of infected patients. ${ }^{9,29-32}$

\section{Recommendations}

1. Restrict individuals with symptoms of $C$. difficile-associated diarrhea, such as fever and bloody diarrhea, from entering the family-centered residential facility.

2. Allow individuals with $C$. difficile-associated diarrhea to enter into the facility once treatment with appropriate antimicrobials has been initiated, their diarrhea has resolved, and they have been without fever and diarrhea for 24 hours. Individuals whose symptoms have resolved do not need a negative $C$. difficile test of their stool to be permitted entry into the facility.

3. Restrict individuals with recent $C$. difficile-associated diarrhea (defined as $C$. difficile diarrhea in the past 1 month) from food preparation and food handling in the common kitchen area.

4. Allow healthy individuals exposed to an individual with C. difficile infection to enter the facility.

5. Refer any guest who develops an illness concerning for $C$. difficile infection for medical evaluation. If $C$. difficile infection is the likely cause, the guest must vacate the facility.

6. Educate individuals exposed to a patient with C. difficileassociated diarrhea about the importance of consistent use of disposable gloves when caring for a child with $C$. difficile-associated diarrhea and hand hygiene after glove removal. It is recommended to thoroughly wash hands with soap and water for at least 40-60 seconds from initiation to drying rather than use alcohol-based hand rub.

7. When a guest with a recent $C$. difficile infection (defined as $C$. difficile diarrhea in the past 1 month) vacates the facility, clean the surfaces of that person's room and bathroom with household bleach diluted with water (1 part bleach and 9 parts water).

\section{Conjunctivitis (Pink Eye)}

Background. Conjunctivitis is an inflammation of the mucous membrane lining the inside surface of the eyelids and 
covering the globe (eyeball) of the eye. The eye appears red and may have a clear or purulent (cloudy, pus-containing) discharge. Acute conjunctivitis has both noninfectious and infectious causes. Infectious etiologies may include either bacterial or viral pathogens. Bacterial pathogens commonly include respiratory bacteria, such as Streptococcus pneumoniae, Haemophilus influenzae, and Moraxella catarrhalis, as well as Staph aureus. The most common viral pathogens include adenovirus and enterovirus; however, other viruses, such as influenza, herpes simplex virus, measles, and rubella, may also cause conjunctivitis.

Conjunctivitis is a relatively infrequent cause of healthcareassociated infection; ${ }^{33}$ however, in neonates conjunctivitis is more common and can be associated with serious invasive disease involving multiple organs. ${ }^{34,35}$ Many large, community-based outbreaks of conjunctivitis have been documented. ${ }^{36,37}$ School-aged children and those living in crowded urban areas have been identified as groups at high risk for infection in such events. ${ }^{38,39}$ Elementary schools, ${ }^{40}$ college campuses, ${ }^{41}$ and military facilities ${ }^{42,43}$ have also been the site of reported outbreaks.

The viruses and bacteria that most commonly cause conjunctivitis are transmitted by hand-to-eye contact from hands that are contaminated with the infectious eye drainage, from contaminated objects (shared towels and washcloths, eye drop solution, or contact lens solution), and potentially by direct inoculation into the eye via large respiratory droplets from an ill individual who is coughing. Infected individuals should be presumed contagious until symptoms have resolved. Transmission may be reduced by careful hand hygiene. The AAP recommends that "except when viral or bacterial conjunctivitis is accompanied by systemic signs of illness, infected children should be allowed to remain in school once any indicated therapy is implemented, unless their behavior is such that close contact with other students cannot be avoided." ${ }^{44}$

\section{Recommendations}

1. Restrict individuals with severe conjunctivitis (ie, copious eye discharge, eye irritation causing frequent eye rubbing or itching, or conjunctivitis accompanied by fever or respiratory symptoms) from entering the facility.

2. Allow individuals with mild conjunctivitis (pink eye with no active discharge, minimum eye irritation, and no fever) to enter the facility, but require such guests to confine themselves to their personal room until symptoms have resolved.

3. Allow healthy individuals exposed to a person with conjunctivitis to enter the facility. No special precautions are required.

4. Educate all family members about the importance of frequent hand hygiene, avoidance of sharing personal items (eg, towels and washcloths, eye drops, and contact lens solutions), and prompt removal and careful handling of contaminated items (eg, tissues, towels, and linens).

\section{Diarrheal Illness with/without Vomiting: Bacterial or Viral}

Background. Diarrhea may be caused by many infectious and noninfectious etiologies. Acute infectious diarrhea is often accompanied by fever, vomiting, and loose stools (that take the shape of a container), sometimes containing blood or mucus. Some specific viral and bacterial causes of diarrhea are associated with potentially severe illness and are easily transmitted. These organisms are transmitted by direct contact with infected feces or objects that have been contaminated with feces (eg, diapers, clothing, linens, and toys).

Two viruses of note for ease of transmissibility are rotavirus and norovirus. Rotavirus diarrhea is a disease primarily of infants. The incidence of rotavirus in infants has decreased since the reintroduction of the rotavirus vaccine in 2006 , but it is important to be aware that shifts in the specific serotypes could cause an increase in the incidence of disease. Norovirus is known as the "cruise ship virus" and is noteworthy for ease of transmission among healthy individuals of all ages.

\section{Recommendations}

1. Restrict individuals with acute diarrhea from the familycentered residential facility until they have met the following 2 criteria: fever-free and diarrhea-free (without the use of antidiarrheal medications) for at least 24 hours.

2. Restrict individuals with the following types of bacterial diarrhea (or bacterial colitis, a more severe form of diarrhea) until they receive written medical clearance for entry: Shiga toxin-producing Escherichia coli (including $E$. coli O157:H7), Shigella, and Salmonella serotype Typhi (the cause of typhoid fever). Individuals who are healthy but are known to be shedding these specific bacteria should also be excluded until they receive written medical clearance for entry.

3. Restrict individuals from entry with proven norovirus or rotavirus infection, because both viruses are easily spread from person to person and have a high risk of causing outbreaks. Younger children, especially those who are diapered, may shed high concentrations of these viruses in their stools and pose a higher risk of transmission to others compared with older children and adults. ${ }^{45,46}$ Environmental cleaning and disinfection is especially important when these viruses cause diarrhea.

4. Some types of bacterial diarrhea require antibiotic treatment and some types do not. Thus, antibiotic treatment is not necessarily a requirement for entry to the facility.

5. Restrict individuals with diarrheal illness occurring within the previous 2 weeks from food preparation and food handling in the common kitchen area.

6. Allow healthy individuals exposed to a person with diarrhea to enter the facility. 
7. Educate all family members about the importance of frequent hand hygiene and appropriate, prompt removal and careful handling of contaminated items (eg, diapers, clothing, and linens). Washing hands with soap and water for 40-60 seconds from beginning to drying rather than use of alcohol-based hand rub is preferred when hands are visibly soiled.

8. Refer any individual who develops acute diarrhea for medical evaluation. Until they are evaluated, require that the symptomatic individual and their asymptomatic family members restrict themselves to their private room.

9. In severe or outbreak situations, additional restrictions may be enforced by the local health department or affiliated medical facility.

\section{Diphtheria}

Background. Diphtheria is an infection caused by the bacterium Corynebacterium diphtheriae. This vaccine-preventable disease is rare in developed countries but remains an important cause of life-threatening disease in Africa, Latin America, Asia, the Middle East, and parts of Europe, where vaccination coverage is suboptimal. ${ }^{47}$ Severe diphtheria is associated with upper airway obstruction, myocarditis (severe inflammation of heart muscle), and nerve damage. ${ }^{47}$

\section{Recommendations}

1. Restrict individuals with confirmed or suspected diphtheria from the family-centered residential facility. Allow entry into the facility when they are proven to be no longer contagious. Require written medical clearance from a healthcare provider or local public health department, stating that they are no longer contagious (this includes written documentation of completing the recommended course of antibiotics (usually at least 10 days of antibiotics, depending on the specific disease) and 2 negative cultures proving eradication of bacteria. ${ }^{47}$

2. Regardless of their immunization status, restrict healthy individuals exposed to a person with confirmed or suspected diphtheria from the facility until they obtain written medical clearance from a healthcare provider or public health department, stating that they are not a risk for transmitting the infection.

3. Refer individuals who develop symptoms of diphtheria for medical evaluation. Instruct the individual and family members to vacate the facility immediately. Contact the local public health department for further instruction. If the individual is diagnosed with diphtheria, notify the public health department and the program manager immediately. The program manager should identify, notify, and instruct exposed guests to contact their healthcare provider and public health department. Postexposure testing and prophylactic treatment may be recommended, regardless of immunization status.

\section{Hepatitis A}

Background. Hepatitis A is an illness associated with fever, fatigue, jaundice (yellow skin), poor appetite, and nausea. Severe liver disease is rare and usually occurs in people with underlying chronic conditions. ${ }^{48}$

Individuals with acute hepatitis $\mathrm{A}$ infection are most infectious during the 1-2 weeks before they develop jaundice or other symptoms. ${ }^{48}$ The virus is excreted in the stool at high levels during those 1-2 weeks, then the amount of virus decreases substantially by 1 week after the onset of jaundice. A hepatitis A vaccine is available to people older than 1 year of age and is highly effective in preventing this infection.

\section{Recommendations}

1. Restrict individuals with hepatitis A infection until they receive written medical clearance for entry into the family-centered residential facility, stating that it has been at least 1 week since illness onset and the patient is no longer contagious.

2. Allow healthy individuals exposed to a person with hepatitis $A$ to enter the facility only if the healthy individual is vaccinated against hepatitis A ( 2 doses of vaccine). Outbreaks of hepatitis $A$ can occur in unvaccinated households, and the incubation period can be prolonged (1550 days). ${ }^{48}$

3. Educate all family members about the importance of frequent hand hygiene and appropriate, prompt removal and careful handling of contaminated items (eg, diapers, clothing, and linens). Washing hands with soap and water for 40-60 seconds from beginning to drying, rather than use of alcohol-based hand rub, is preferred if visibly soiled with feces.

4. Refer individuals who develop symptoms of hepatitis A for medical evaluation. Instruct the individual and family members to vacate the facility immediately. If the individual is diagnosed with hepatitis $\mathrm{A}$, notify the local public health department and program manager immediately. The program manager should identify, notify, and instruct exposed guests to contact their healthcare provider or public health department. Exposed individuals may require postexposure vaccination or immunoglobulin. ${ }^{48}$

5. In severe or outbreak situations, additional restrictions may be enforced by the local health department or affiliated medical facility.

\section{Hepatitis B, Hepatitis C, and Human Immunodeficiency Virus (HIV)}

Background. Hepatitis B virus (HBV) can cause both acute and chronic liver disease. Some patients may appear healthy, but others may be ill with nausea, vomiting, jaundice (yellowing of the skin), or in some cases severe liver disease. ${ }^{49}$ Chronic infections may lead to cirrhosis (scarring of the liver), liver failure, and cancer. ${ }^{50} \mathrm{HBV}$ is spread by exposure 
to infected blood or body fluids. Transmission from an infected individual can occur by transfusion of blood that has not been screened for HBV, injection drug use, needlestick injuries, and sexual contact with an infected person. HBV can also be spread from mother to infant during pregnancy or at the time of birth. ${ }^{49,50}$ Transmission of HBV infection in child care settings has been described but occurs rarely. Such transmission is most likely to occur through direct contact with blood from an infected person after an injury or from bites or scratches that break the skin. ${ }^{23}$ There is a 3-dose vaccine regimen that protects against hepatitis $B$ virus, the first dose of which is recommended in the United States for all infants at the time of birth or before being discharged from the nursery. See Appendix B ("Vaccines") for more information.

Hepatitis $\mathrm{C}$ virus (HCV) is another virus that causes both acute and chronic liver disease. Chronic infections may lead to liver failure and cancer. ${ }^{51}$ Persons who are infected with $\mathrm{HCV}$ may feel well and not know they are infected..$^{52} \mathrm{HCV}$ is spread by exposure to infected blood or body fluids. The most common risk factors are injection drug use, a history of multiple sex partners, and a history of receipt of a blood transfusion prior to 1992 . HCV can also be spread from mother to infant and rarely by household contact. ${ }^{51,52}$ The transmission risks of HCV infection in child care settings are unknown but are likely to be extremely low. ${ }^{23}$ There is currently no vaccine available to protect against $\mathrm{HCV}$ infection.

HIV causes an infection that attacks the immune system. It causes a variety of clinical manifestations and, in its advanced stage, acquired immunodeficiency syndrome (AIDS), which is associated with an increased risk of many life-threatening infections. ${ }^{53}$ Transmission of HIV occurs only by contact with blood or certain body fluids (eg, semen, vaginal secretions, and human milk). Transmission does not occur by casual contact and has not been documented in settings such as school or child care. ${ }^{53}$ There is currently no vaccine to protect against HIV infection, but there are effective medications that greatly reduce the risk of transmission from person to person.

\section{Recommendations}

1. Allow individuals infected with $\mathrm{HBV}, \mathrm{HCV}$, or HIV to enter the family-centered residential facility without restriction, except for the following special situations:

a. Restrict entrance of an individual with $\mathrm{HBV}, \mathrm{HCV}$, or HIV infection and open skin lesions that cannot be covered or other conditions that might allow contact with their body fluids.

b. If an infected person or their family member has behaviors (eg, biting) that might put others at risk of contact with their blood or body fluids, specific restrictions may be required and should be determined on an individual basis. ${ }^{23,54}$

2. Allow healthy individuals who have been exposed to a person infected with $\mathrm{HBV}, \mathrm{HCV}$, or HIV to stay at the facility without restriction.

3. Educate families about the importance of appropriate, prompt disposal of items contaminated with blood and/or body fluids (eg, bandages, sanitary pads or tampons, and items that have been used for injection of medication). ${ }^{43,53}$

4. Educate family members about the importance of good hand hygiene, appropriate glove use, and appropriate handling of blood and body fluids. ${ }^{54}$ Advise that they should not share personal items such as toothbrushes or razors with others. Contaminated items should be handled following standard precautions.

\section{Herpes Simplex Virus (HSV) Infections}

Background. Herpes simplex viruses (HSV) cause a spectrum of clinical infections, including cold sores or "fever blisters" (herpes labialis); painful skin rashes characterized by clusters of small, fluid-filled blisters; and genital rashes or ulcers. ${ }^{55}$ The occurrence of HSV lesions localized to the fingers or toes is called herpetic whitlow. A severe HSV skin rash can develop in individuals with eczema (eczema herpeticum). Primary HSV gingivostomatitis is a common infection in young children associated with many painful mouth ulcers in and around the mouth, drooling, high fever, and swollen lymph nodes in the neck. ${ }^{55} \mathrm{HSV}$ can cause severe, life-threatening disease in young infants, affecting the brain, liver, and lungs. ${ }^{55}$ Skin rash may or may not be present in newborns infected with HSV. HSV can also cause encephalitis or meningitis in older children and adults. HSV is an uncommon cause of conjunctivitis. People with cold sores are advised to avoid kissing newborns or immune-compromised individuals.

Like the varicella-zoster (chickenpox or shingles) virus, HSV remains latent in the body after the first infection. For this reason, recurrences of HSV-related skin rashes or cold sores are common. Recurrent episodes of oral HSV may not be obvious; the virus may be present in saliva even in the absence of visible lesions. ${ }^{55}$ The virus is spread though contact with infected lesions or contaminated secretions.

\section{Recommendations}

1. Allow healthy individuals with isolated labial (lip) cold sores to enter the family-centered residential facility, as long as the individual is capable of frequent hand hygiene according to the recommended procedure and can follow instructions not to kiss others. If the individual is young or incapable of hand hygiene, then either restrict the individual from entrance until the cold sore is completely crusted and dry or confine to the individual's room.

2. Restrict individuals with active HSV skin or eye lesions from entering the facility until written medical clearance from a healthcare provider is obtained. In general, the individual must be able to completely cover the rash with 
clothing, bandage, or other appropriate dressing. If the rash is unable to be completely covered, restrict entrance to the individual until the rash is completely crusted and dry. If entry is permitted, confine the individual to his or her private room until lesions are completely crusted and dry.

3. Restrict those with primary herpetic gingivostomatitis from the facility if active lesions and drooling are present. Once the individual has recovered from the illness, written medical clearance from a healthcare provider is required, stating that the patient does not pose an infectious risk to others.

4. Allow healthy individuals who have been exposed to a person infected with HSV to stay at the facility without restriction.

5. Educate family members about the importance of frequent hand hygiene, avoidance of sharing personal items, and prompt removal and careful handling of potentially contaminated items (eg, tissues, towels, and linens). Advise family to avoid direct, close contact with lesions to prevent person-to-person transmission.

\section{Lice}

Background. Head lice infestation is common, particularly among school-aged children of all socioeconomic groups. ${ }^{56,57}$ Head lice are small, wingless insects (about the size of a sesame seed) that prey on the blood of humans. ${ }^{57}$ Head lice lay eggs (nits) in an individual's scalp, where they remain firmly attached to the hair shaft until they hatch by a sticky substance produced by the louse. The nits are incubated by body heat. Once hatched, the louse injects saliva into an individual's scalp during feeds. Over time, louse saliva can cause the scalp to become irritated and lead to scalp itching, which is the most common symptom encountered during head lice infestation. However, because scalp itching may not develop for several weeks after becoming infested, many individuals are initially asymptomatic. Occasionally, skin breakdown from scratching the affected site may result in a bacterial infection of the scalp.

Head lice do not fly or hop; rather, they move by crawling. ${ }^{56}$ Therefore, transmission is most likely to occur from direct contact with the head of an infested individual, such as from sleeping in the same bed..$^{56,57}$ Head lice can also be transmitted from sharing of personal items that have contact with the head, such as combs, brushes, pillows, and hats. However, because lice do not survive when away from the scalp for more than a day, transmission is less likely to occur by this method. Of note, head lice do not transmit other infectious agents. ${ }^{57}$

\section{Recommendations}

1. Restrict individuals with untreated head lice from entering the family-centered residential facility.
2. Refer individuals with suspected head lice for evaluation by a healthcare provider before facility entry. If the diagnosis is confirmed, the individual should undergo treatment as recommended by their healthcare provider. Once treatment has been completed, allow the individual to enter the facility. Instruct the family to keep the individual's personal items, such as combs, brushes, hats, and pillows, inside their private room.

3. Encourage asymptomatic bedmates of infested individuals to receive prophylactic treatment for head lice.

4. Allow healthy, asymptomatic family members of someone with head lice to enter the facility as long as they have been evaluated and active lice infestation has been excluded.

5. Refer any guest who develops symptoms of head lice for evaluation. Until they are evaluated, restrict the symptomatic individual and their asymptomatic family members to their private room.

6. Launder bed linens with hot water (ie, greater than $130^{\circ} \mathrm{F}$ ), thoroughly clean the room surfaces, and vacuum the floor and furniture. Place any items that cannot be laundered (eg, stuffed animals and pillows) in a plastic bag for 2 weeks prior to reuse.

\section{Measles}

Background. Measles is a highly contagious viral infection that is transmitted by inhalation of respiratory droplets when infected individuals cough or sneeze. It commonly presents with symptoms of fever, cough, nasal congestion, conjunctivitis (pink eye), and a red rash that begins on the face then spreads to the entire body. The measles virus (rubeola) can also cause ear infections, pneumonia, croup, hepatitis, encephalitis, and diarrhea. Measles infection is rare in developed countries because of routine childhood immunization. However, measles remains a leading cause of childhood disease and death globally. Outbreaks have occurred during the past several years due to importation of disease by travelers and infections in individuals who are incompletely immunized. ${ }^{58}$

Individuals are contagious from 1 to 2 days before the onset of symptoms until 4 days after the rash appears. ${ }^{9,23,58}$

\section{Recommendations}

1. Restrict individuals with confirmed or suspected measles from the family-centered residential facility. Allow entry into the facility when they are no longer contagious, usually 4 days after the appearance of the rash. ${ }^{9}$ Require written medical clearance from a healthcare provider or local public health department, stating that they are no longer contagious. ${ }^{23,58}$

2. Restrict healthy individuals exposed to a person with confirmed or suspected measles from the facility until they 
obtain written medical clearance from a healthcare provider or public health department, stating that they are not a risk for transmitting the infection.

3. Refer individuals who develop symptoms of measles for prompt medical evaluation. Instruct the individual and family members to vacate the facility immediately. Contact the local public health department for further instruction. If the individual is diagnosed with measles, notify the public health department and the program manager immediately. The program manager may be asked to identify, notify, and instruct exposed guests to contact their healthcare provider and public health department. Postexposure prophylactic treatment must be administered to high-risk exposed individuals within 6 days of exposure.

\section{Meningitis, Bacterial or Viral}

Background. Bacterial meningitis is a serious bacterial infection of the membranes that cover the brain and spinal cord characterized by fever, severe headache, vomiting, and neck stiffness. Bacterial meningitis can lead to hearing loss, brain damage, and learning disabilities.

Most types of bacterial meningitis are not easily spread from person to person. However, there are 2 specific types of bacterial meningitis, Haemophilus influenza type $b$ (Hib) and Neisseria meningitidis (meningococcal) meningitis, that can be contagious to close contacts. Both bacteria can also cause other types of serious infections, such as bloodstream infections. Hib infections are rare because there is a vaccine that protects against this infection. Meningococcal vaccines are available but do not prevent infection caused by all strains of this group of bacteria. The bacteria can be spread from person to person by inhaling or having direct contact with infected respiratory tract secretions. ${ }^{59,60}$ This can occur through coughing, kissing, and sneezing. People who have close contact with a person who is sick with Hib or meningococcal meningitis are at increased risk of contracting the disease. ${ }^{59,60}$ Exposed contacts are sometimes given prophylactic antibiotics to prevent them from becoming sick with the same bacteria; $;^{59,60}$ a physician or the local public health department will determine if an exposed person qualifies for postexposure prophylaxis and which antibiotic to prescribe. Streptococcus pneumoniae, another bacterium that causes bacterial meningitis, is not spread from person to person.

Viral meningitis is an illness characterized by fever, headache, vomiting, and neck stiffness. Unlike bacterial meningitis, most types of viral meningitis are usually not as severe and are not as easily spread from person to person. Enteroviruses are common causes of viral meningitis and are spread through direct contact with stool (diarrhea) and respiratory fluids (coughing and saliva) or by touching items contaminated with stool or respiratory secretions. ${ }^{61}$ Some types of viral meningitis are transmitted by mosquitoes (eg, West Nile virus) and are not spread person to person.

\section{Recommendations}

1. Allow individuals who have been discharged from the hospital after treatment for bacterial meningitis entry into the family-centered residential facility providing they meet all other criteria. Once a child with bacterial meningitis has received 24 hours of antibiotic therapy and is discharged from the hospital, he or she is no longer contagious.

2. Allow healthy individuals who have been exposed to a person with bacterial or viral meningitis to enter the facility without restriction.

3. Refer healthy exposed individuals to the child's healthcare provider or public health department to determine if he or she qualifies for postexposure antibiotics to prevent the disease. Allow individuals who are prescribed postexposure antibiotics entry into the facility. The antibiotics may be indicated for the exposed person's own health safety. Thus, the exposed person does not pose a risk to others.

4. Immediately refer any guest who develops an illness concerning for meningitis for medical evaluation. Notify the program manager if it is determined that the person has either Hib or meningococcal disease (see "Background" above). In such cases, the program manager should identify, notify, and instruct exposed guests to contact their healthcare provider immediately to determine if they qualify for postexposure antibiotic prophylaxis.

5. Restrict entrance to the facility to individuals who have been discharged from the hospital after treatment for viral meningitis until they are fever-free for 24 hours and diarrhea (if present) has completely resolved.

\section{Multidrug-Resistant Bacteria (MDRO): People Known to Be Colonized}

Background. Bacteria that have become resistant to the common antibiotics used to treat infections are referred to as multidrug-resistant organisms (MDROs). Some people may have an MDRO living on their skin or in their bodies but are not ill. This is called bacterial colonization. People can be colonized with an MDRO transiently, intermittently, or persistently over several months. ${ }^{62,63}$ People with chronic medical conditions (eg, cancer, kidney failure, and transplant recipients) are at highest risk of acquiring an MDRO.

Methicillin-resistant Staphylococcus aureus (MRSA), one of the most well-known MDROs, is a type of bacteria that is resistant to many antibiotics. MRSA infections frequently involve the skin, causing boils or abscesses. Healthy individuals may have MRSA bacteria living inside their nostrils or on their skin. MRSA can also cause very serious disease, including pneumonia, infection of bones and joints, and abscesses deep within the body. MRSA may be spread person to person when there is close contact with the infected fluid or pus that is draining.

Vancomycin-resistant enterococcus (VRE) is a different type of bacteria that lives in the intestines of some people 
and can sometimes cause infection; VRE infections are rare in children and usually occur in people with chronic illness, such as cancer. ${ }^{64,65}$

There are other bacteria, called gram-negative bacteria, that have developed resistance to many antibiotics. These highly resistant bacteria can be found in the intestines of some people and may cause infections. These bacteria are usually identified when a patient is hospitalized, but when studied, many healthy people in the community have been found to be colonized with these resistant bacteria.

There may be special circumstances when a referring hospital has experienced high transmission rates of a specific MDRO; therefore, additional restrictions may be recommended by the facility's IPC department.

\section{Recommendations}

1. Allow individuals known to be "colonized" with an MDRO entry to the family-centered residential facility as long as the person is currently healthy, is able to follow recommended hygienic practices, and is able to contain their body fluids (eg, stool).

2. If a family-centered residential facility or its referring medical facility has experienced high transmission rates of a specific MDRO, additional restrictions may be considered. Consultation with local IPC specialists is recommended.

3. If the individual has a specific disease caused by an MDRO (eg, skin infection or respiratory infection), please refer to the specific disease section for more guidance.

4. Allow healthy individuals exposed to a person known to be colonized with an MDRO entry to the facility without restriction.

5. Educate all family members about the importance of frequent hand hygiene and appropriate removal and careful handling of contaminated items (eg, diapers, clothing, and linens).

\section{Mumps}

Background. Mumps is a viral infection that presents with swelling of 1 or more salivary glands of the head and neck, usually the parotid glands, which are located on the face, immediately in front of the earlobes. Rarely, it can cause complications affecting other organ systems of the body. ${ }^{66}$

Mumps is transmitted by respiratory droplets generated during coughing or sneezing. Individuals are most contagious from 1 to 2 days before parotid gland swelling until 5 days after the onset of symptoms. ${ }^{9,67}$ Mumps can be prevented by vaccination.

\section{Recommendations}

1. Restrict individuals with mumps from the family-centered residential facility until it has been at least 5 days from the onset of parotid gland swelling and they obtain written medical clearance from a healthcare provider. ${ }^{9}$

2. Restrict healthy individuals exposed to a person with mumps from entry into the facility until they obtain written medical clearance from a healthcare provider, stating that they are not a risk for transmitting the infection. ${ }^{23}$ Exposed individuals can become ill with mumps anywhere from 12 to 25 days after exposure. ${ }^{67}$

3. Refer individuals who develop symptoms of mumps for medical evaluation. Instruct the individual and family members to vacate the facility immediately. If the individual is diagnosed with mumps, notify the local public health department and program manager immediately. The program manager should identify, notify, and instruct exposed guests to contact their healthcare provider or public health department.

\section{Pertussis}

Background. Pertussis is a prolonged cough illness caused by Bordetella pertussis. The typical incubation period is 710 days, although rarely it may be as long as 21 days. Initial signs are nonspecific and include runny nose, sneezing, and possibly low-grade fever. Although cough in this initial, or catarrhal, phase is variably present and mild, there is a high burden of organisms in the nose and throat, increasing the likelihood of transmission to others. During the paroxysmal phase of pertussis, some patients manifest the classic signs of pertussis, including severe, episodic cough; inspiratory whoop; and forceful coughing followed by vomiting. Young infants may present with feeding difficulties or apnea (breath holding) during coughing spells. Infection may be life threatening or fatal in infants who are too young to be protected by immunization and have very small airways.

Immunity wanes 5-10 years after immunization, leaving adolescents and adults susceptible to this infection. ${ }^{67} \mathrm{Al}-$ though adolescents or adults may develop classic pertussis, they may have only mild cough that resembles a "smoker's cough," bronchitis, or asthma. ${ }^{68}$

Bordetella pertussis is spread by respiratory droplets; outbreaks of pertussis have been reported in hospitals, ${ }^{69}$ schools,${ }^{70}$ child care centers, ${ }^{71}$ and other residential facilities. ${ }^{72}$ Transmission occurs when large droplets containing infectious microorganisms are expelled during coughing or sneezing and subsequently contact the mouth, nasal mucosa, or eyes of a susceptible host. Transmission may also occur when the mucous membranes are touched with unwashed contaminated hands after contact with infectious secretions or an object contaminated with secretions. Patients without classic or severe symptoms may transmit pertussis. ${ }^{73}$ If not treated with appropriate antibiotics, infected people typically remain infectious during the first 3 weeks of cough. 


\section{Recommendations}

1. Restrict individuals with pertussis from the family-centered residential facility until treatment has been completed and written medical clearance is obtained from a healthcare provider. Persons with pertussis are contagious until they have completed 5 days of appropriate antibiotic therapy, most often a specific antibiotic such as azithromycin. ${ }^{74}$ Cough may persist for many weeks after effective treatment and is not a reason for continued exclusion from the facility.

2. During the initial routine screening process upon facility entry, screen family members and other close contacts of infected children for respiratory symptoms, because infants and young children commonly acquire pertussis from a family member who has not yet sought medical care for cough illness. ${ }^{75}$

3. Restrict healthy individuals exposed to pertussis from the facility until active infection has been excluded and prophylactic antibiotics have been started. Written medical clearance from a healthcare provider is required. Specific antibiotics (eg, azithromycin or erythromycin) can prevent the development of pertussis in susceptible individuals who are exposed to pertussis.

4. Restrict healthy individuals exposed to pertussis who refuse or are unable to take prophylactic antibiotics for 21 days after the last pertussis exposure. Written medical clearance from a healthcare provider is required.

5. When a case of pertussis is identified in a guest, staff member, or volunteer, identification of exposed persons is essential so that prophylactic antibiotics can be prescribed by their medical care provider or local health department. ${ }^{74}$ In this situation, notify the program manager immediately. Exposed guests should be identified, notified, and instructed to contact their healthcare providers. The local public health department may also assist with this task.

6. Vaccines are available to prevent pertussis in children and adults. A single dose of tetanus toxoid-reduced diphtheria toxoid- and acellular pertussis (Tdap) vaccine is recommended for all adults who have close contact with infants younger than 12 months of age. ${ }^{76}$

\section{Rashes of Unknown Cause}

Background. Skin rashes can have many different causes, including bacteria, viruses, fungi, parasites, allergies, medications, insect bites, and medical conditions. A rash can sometimes be the sign of a contagious infection. However, a rash that develops without fever or other signs or symptoms of acute illness is usually not indicative of a contagious infection. ${ }^{23}$

\section{Recommendations}

1. Refer individuals with a rash and fever for medical eval- uation. Manage entry, or reentry, into the family-centered residential facility for each case on an individual basis, based on recommendations of the healthcare provider.

\section{Respiratory Diseases}

Background. Respiratory diseases may present as upper tract disease, such as "the common cold," sinusitis, or croup, or they may manifest as lower tract disease, such as pneumonia or bronchiolitis. Lower tract respiratory disease can be associated with substantial morbidity and mortality, the risk of which depends on the age of the patient, underlying disease, and the organism causing the infection.

Upper respiratory tract infections are most commonly caused by respiratory viruses, including adenovirus, rhinovirus, RSV, human metapneumovirus, influenza viruses, parainfluenza viruses, and coronaviruses. Lower respiratory tract infections can be caused by either viruses or bacteria. In infants and severely immune-compromised individuals, these viruses can cause severe lower tract disease. RSV bronchiolitis is the most common cause of hospitalization for respiratory disease in infants. ${ }^{77}$ In severely immune-compromised individuals, RSV pneumonia carries high morbidity and mortality ${ }^{78}$ and can be associated with large outbreaks. ${ }^{79}$ In both children and adults, bacterial pathogens such as Streptococcus pneumoniae and atypical bacteria such as Mycoplasma pneumoniae and Legionella cause pneumonia.

Most respiratory viruses are spread by respiratory droplets through coughing and sneezing. For certain respiratory viruses, such as RSV, direct contact with infected respiratory secretions or objects contaminated with respiratory secretions is another way the virus can be spread. Bacterial causes of respiratory disease are spread by respiratory droplets before patients have received 24 hours of effective antibiotics.

It is important to be aware of epidemics of respiratory tract viruses, most frequently influenza virus in various worldwide locations. For example, epidemics caused by the SARS virus (severe acute respiratory syndrome $\mathrm{CoV}$ ) of 2003 began in Asia but spread to other continents. Similarly, pandemic influenza A (H1N1) 2009 virus had a worldwide distribution with foci of infection changing over time. Various different bird influenza viruses have circulated in China but have not spread far. The local health department sends alerts to the healthcare community when there is risk of a dangerous virus being introduced into a specific community.

Influenza is the only respiratory tract virus for which a vaccine is available and recommended annually for all individuals 6 months of age and older. High-risk prematurely born infants may receive a monthly dose of RSV antibody (palivizumab, or Synagis) during the RSV season to prevent severe disease and hospitalization if they meet the criteria defined by the AAP. 


\section{Recommendations}

1. Restrict individuals with viral respiratory illness from entering the family-centered residential facility until they have been fever-free for 24 hours without antifever medication. Require the guest to restrict themselves to their private room until all symptoms (eg, runny nose, cough, and congestion) are resolved.

2. Restrict individuals diagnosed with bacterial pneumonia from facility entry until they have received 24 hours of effective antibiotics and have been fever-free for 24 hours, with the exception of Legionella. Allow entry for patients with Legionella pneumonia, because it is not transmitted from person to person. See "Pertussis" for specific information about management of persons diagnosed with pertussis.

3. Allow healthy individuals exposed to a person with a respiratory illness to enter the facility. See "Pertussis" for specific information about management of persons exposed to pertussis.

4. Educate all family members about the importance of cough etiquette, frequent hand hygiene, and appropriate removal and careful handling of contaminated items (eg, tissues, clothing, linens, and toys).

5. From the time when the influenza season is approaching and influenza vaccine becomes available in a community, take the opportunity to remind families of the importance of getting influenza vaccine. A new vaccination is required each year. It would be especially helpful for families to be directed to places where they can obtain vaccine.

\section{Scabies}

Background. Scabies is an itchy skin infestation caused by the mite Sarcoptes scabiei var. hominis. Common symptoms include itching and a bumpy rash between the fingers and toes, around the wrists and the elbows, under the breasts, and in the genital area. ${ }^{80}$ Rash may also occur on the head, neck, palms, and soles in children. Crusted or Norwegian scabies is a severe form of scabies that affects primarily the elderly and those who are immune compromised. Outbreaks of scabies, especially crusted scabies, have occurred in hospitals, ${ }^{81}$ nursing homes, ${ }^{82}$ and other residential facilities, sometimes lasting for several months.

Scabies is usually transmitted by prolonged skin-to-skin contact with an infected person. ${ }^{80}$ Occasionally, contact with contaminated items such as clothing or linen can result in transmission. Individuals with crusted scabies are very infectious because of the large number of mites present.

\section{Recommendations}

1. Restrict individuals with untreated scabies from entry to the family-centered residential facility.

2. Allow individuals to enter the facility once treatment has been completed (usually overnight). Itching may persist for several weeks after scabies treatment and is not a reason for exclusion.

3. Refer all healthy family members/household members of an infected person to a healthcare provider for treatment, but these individuals need not be excluded from the facility unless a rash is present.

4. Wash and dry all clothes and linen used by an affected person in hot water and high heat cycle to kill mites and prevent reinfestation. Place any items that cannot be laundered (eg, stuffed animals and pillows) in a plastic bag and dispose of them.

5. Rooms occupied by guests subsequently diagnosed with scabies do not require application of pesticides. ${ }^{83}$ However, the furniture and carpeting in a room occupied by a person with crusted scabies should be thoroughly cleaned and vacuumed to remove skin crusts and scales that may contain mites.

6. Because crusted scabies is very contagious, a single case in a guest should prompt surveillance for additional cases in guests or staff members. Multiple cases of crusted scabies in guests and/or staff members should prompt notification of the local public health department to assist with control measures.

\section{Skin and Soft Tissue Infections}

Background. Infections of the skin and soft tissues are caused most frequently by Staph aureus (also referred to as "staph") or Streptococcus pyogenes (also referred to as "strep" or "group A strep"). Staph infections may be caused by staph strains that are very susceptible to antibiotics or MRSA (methicillin-resistant Staphylococcus aureus) strains that are resistant to many frequently used antibiotics. The likelihood of a particular organism depends on the type of skin infection (eg, impetigo, cellulitis, or abscess), the cause of infection (eg, unknown, trauma, or animal bite), and the individual's underlying risk factors (eg, previous history of skin infections and immune function). ${ }^{84}$ Many skin infections are easily treated with oral antibiotics alone. Some types of skin infections, especially those caused by Staph aureus, may require a minor surgical procedure to drain pus from an abscess (also called a boil), if present. If the infection is particularly severe, it may necessitate hospital admission for intravenous (IV) antibiotics. ${ }^{84}$ In recent years, there has been an increase in frequency of skin infections due to MRSA, and therefore the spread of MRSA is of particular concern for healthcare facilities. ${ }^{85}$

The risk of transmission of bacteria to others depends on the type of skin infection and the specific bacteria causing the infection. Staph aureus (including MRSA) is easily transmitted from person to person by direct contact with infected fluids, such as pus draining from a boil or the respiratory secretions of an individual with staphylococcal pneumonia. ${ }^{86}$ Individuals can sometimes be colonized, meaning that the 
TABLE 1. Examples of Significant Varicella Exposures in a Family-Centered Residential Setting

Chickenpox
1. Household: residing in the same household during the contagious period
2. Playmate: face-to-face indoor play with an infectious person ${ }^{\mathrm{a}}$
3. Multifamily facility: in the same room, family lounge, or common area with an infectious person ${ }^{\mathrm{a}}$
Zoster (shingles)
1. Intimate contact (eg, touching or hugging) with a person having skin lesions that are deemed contagious
2. Follow the same guidance for chickenpox if the person has disseminated zoster (eg, skin lesions in more
than 1 area of the body, usually in patients with weakened immune systems)

a Minimum duration of exposure needed for transmission of the varicella virus is not clearly defined but may be as short as 5 minutes.

bacteria live in their nose, in their throat, or on their skin but they do not have symptoms of infection. ${ }^{86,87}$ Transmission can be minimized by avoiding direct contact with infected fluids, close attention to hand hygiene, and containment of draining fluid with frequent dressing changes. ${ }^{85}$

\section{Recommendations}

1. If the individual's skin infection is caused by group A streptococcus (GAS), please refer to the following section, "Streptococcal Infections (Including Strep Throat)," for guidance.

2. Restrict individuals with skin and soft tissue infections and active drainage from the infection site. After an individual has a surgical drainage of an infected abscess (boil), allow entry into the facility as long as the skin lesions can be kept completely covered at all times with a clean and dry dressing.

3. Allow healthy individuals exposed to someone with a skin infection entry to the facility without restriction.

4. Refer individuals who develop a skin infection while staying at the facility for medical evaluation. Until evaluated, restrict the individual to his or her private room.

5. Educate all family members about the importance of frequent hand hygiene and appropriate, prompt removal and careful handling of contaminated items (eg, used bandages, clothing, and linens).

\section{Streptococcal Infections (Including Strep Throat)}

Background. Strep throat is caused by group A streptococcal (GAS) bacteria. It most commonly presents as an infection of the throat and tonsils called pharyngitis or tonsillitis. Symptoms include fever, sore throat, and enlarged lymph nodes in the neck. Scarlet fever is a characteristic red, sandpaper-like rash that can occur along with strep throat. ${ }^{88}$

Strep throat can be spread by contact with respiratory secretions or by sharing contaminated objects, such as utensils, cups, and straws. ${ }^{88}$ Individuals are considered contagious until they have been treated with appropriate antibiotics for 24 hours. ${ }^{23}$

\section{Recommendations}

1. Restrict individuals with an active GAS infection from entry to the family-centered residential facility.

2. Allow individuals to enter the facility once they have completed at least 24 hours of antibiotic treatment and are fever-free for 24 hours (without the use of fever-lowering medications)..$^{9,23}$

3. Allow healthy individuals who have been exposed to someone with a documented case of GAS infection or strep throat to enter the facility.

4. Refer exposed individuals who develop symptoms for medical evaluation; they should undergo testing and be treated if that test is positive and the previous steps apply to their entry to the facility. ${ }^{23}$

\section{Tuberculosis}

Background. Tuberculosis (TB) is a disease caused by infection of the lungs and other organ systems with $\mathrm{Myco-}$ bacterium tuberculosis bacteria. After infection with $M$. tuberculosis, the bacteria may remain in the body and not cause disease, called latent TB infection (LTBI). Persons with LTBI have no symptoms and are not infectious. ${ }^{89}$ Sometimes rather than remaining latent, the bacteria will cause active disease. Active disease can occur at any time in a person with untreated LTBI, but it most commonly occurs 1-6 months after infection and is characterized by fever, chills, night sweats, weight loss, and cough. ${ }^{90} \mathrm{~TB}$ is transmitted by small airborne respiratory droplets that may remain suspended in the air and travel long distances. It is usually transmitted only through air and not by contact with surfaces or objects. ${ }^{89}$

LTBI is not contagious. Persons with active TB disease are potentially contagious until they are treated with antituberculosis medications. Follow-up testing is often performed to prove that they are no longer contagious. Persons most at risk of acquiring TB are those who have shared the same air space in a household or other enclosed environment with a person with active TB infection for a prolonged period of time. $^{89}$ 
TABLE 2. Criteria for Individual to Be Considered "Noncontagious" Despite Exposure to Varicella

Individual must meet at least 1 of the following criteria (signed medical clearance required):

1. History of having chickenpox or shingles (diagnosed by a healthcare provider)

2. Documentation of 2 doses of varicella-containing vaccine, separated by at least 3 months

3. Documented varicella antibodies (also known as a positive varicella IgG blood test)

4. It has been at least 21 days since the person's last significant exposure to the person with chickenpox or shingles (if the exposed person received postexposure prophylaxis [IVIG or VariZIG], it must be at least 28 days since last exposure)

\section{Recommendations}

1. Restrict individuals with active tuberculosis from the family-centered residential facility until they have been judged to be noninfectious and they have written medical clearance from the treating healthcare provider or local public health department. Verbal medical clearance by direct telephone consultation with a public health official is also acceptable.

2. Allow persons with latent TB infection (LTBI) to enter the facility without restriction.

3. Restrict entrance to the facility to healthy family members exposed to a person with active TB until they have written medical clearance from the treating healthcare provider or the local public health department. Verbal medical clearance by direct telephone consultation with a health department official is also acceptable.

4. Ask any guest who is newly diagnosed with active TB and his or her family to vacate the facility immediately. Require written medical clearance for readmission to the facility. On the basis of consultation with the public health department, the program manager may be asked to identify and notify all exposed guests and instruct them to seek medical attention. ${ }^{23}$

\section{Varicella-Zoster Virus (Chickenpox and Shingles)}

Background. The varicella-zoster virus is highly contagious and is the cause of both chickenpox and shingles. Chickenpox is characterized by fever and an itchy body rash of fluid-filled blisters on a red base ("dew drops on a rose petal"). The rash is typically scattered over the body, including the scalp, and it eventually forms scabs. The severity of disease increases with age and is most severe in those with weakened immune systems. ${ }^{91}$ Chickenpox may be complicated by pneumonia, brain inflammation (encephalitis), or bacterial infections. ${ }^{91}$ After chickenpox, the varicella-zoster virus remains dormant in the body. Routine vaccination against varicella reduces the risk of acquiring chickenpox.

Shingles (also called herpes zoster) is an illness that occurs when the latent varicella-zoster virus becomes active again. Shingles is characterized by clusters of very painful blisterlike skin lesions that can develop anytime in a person's lifetime but that most commonly occur after the age of 60 years or during periods of immune compromise. Pain may persist long after the lesions of shingles have healed.
A person with chickenpox is highly contagious starting from 2 days before the first onset of rash until all blisters are completely dried and crusted. ${ }^{91}$ During chickenpox, the virus is transmitted via respiratory secretions and direct contact with the skin lesions. In a household setting, chickenpox has a secondary transmission rate to susceptible individuals of up to $96 \% ;^{92}$ in the hospital setting, the secondary transmission rate ranges from $4.5 \%$ to $29 \% .^{93}$ At least 1 hospital outbreak involving a family-centered residential facility has been reported. ${ }^{3}$

A person with shingles is contagious until all blisters are completely dried and crusted. During an episode of shingles the virus is transmitted via direct contact with the skin or contaminated items. In immune-compromised patients, the virus may be present in respiratory tract secretion if disseminated zoster develops, and the rash may be present on both sides of the body. Person-to-person transmission has been described in hospital ${ }^{94}$ and adult long-term care facility ${ }^{95}$ settings. However, if an individual has a healthy immune system and localized lesions that can be covered, it is unlikely that transmission will occur.

\section{Recommendations for chickenpox}

1. Restrict individuals with active chickenpox from entrance to the family-centered residential facility.

2. Once the rash is completely crusted and the patient is without fever, allow an individual with chickenpox to enter the facility without restriction; written medical clearance from a healthcare provider is required prior to facility entry, stating that the rash is completely crusted and the person is no longer contagious.

3. Significant exposures to chickenpox are defined in Table 1. ${ }^{91}$ Restrict persons who have been recently exposed to chickenpox until the criteria in Table 2 are met. Prior to entry, require written medical clearance from a healthcare provider that documents why the exposed individual is not contagious. To be considered noncontagious, 1 of the following 4 criteria must be met (see Table 2 ): ${ }^{96}$ (1) the person has a past history of having had chickenpox or shingles (diagnosed by a healthcare professional); (2) the person has documentation of 2 doses of varicella-containing vaccine, separated by at least 3 months; (3) the person has documented varicella antibodies (also known as a positive varicella IgG blood test); or (4) it has been at least 21 days since the person's last significant exposure 
to the person with chickenpox (if the exposed person received postexposure prophylaxis [IVIG or VariZIG], it must be 28 days since the last exposure).

4. Request that individuals with suspected chickenpox vacate the facility immediately and seek medical evaluation. Require written medical clearance to return.

5. Individuals with chickenpox are considered contagious during the 2 days before the first appearance of rash. ${ }^{91}$ If an individual diagnosed with active chickenpox entered the facility anytime during the 2 days before rash onset (or while the person has a rash), notify the program manager immediately. The program manager must identify and notify exposed guests and instruct them to immediately consult a healthcare provider to determine if postexposure prophylaxis is recommended.

\section{Recommendations for shingles}

1. Allow individuals with an active case of shingles to enter the family-centered residential facility only if there is written confirmation that the following criteria are met: (1) the rash is localized on one side of the body and can be completely covered by a dressing and/or clothing, (2) the person has a normal immune system, (3) the person is not taking medications that can weaken his or her immune system, and (4) the person is capable of frequent hand hygiene and understands the importance of caring for the lesions and dressings in such a way as to contain the lesions. If all criteria cannot be met, then the individual should be restricted from the facility.

2. If the individual with shingles meets criteria to allow entry, restrict the individual to his or her private room at all times until the rash is completely crusted.

3. Educate all family members about the importance of frequent hand hygiene and appropriate disposal of potentially contaminated items (eg, dressings, clothing, and linens).

4. People nonimmune to varicella can get chickenpox if directly exposed to shingles. Interview individuals recently exposed to a person with shingles about the level of exposure to the skin lesions. If the person's exposure was significant (see Table 1), then require written medical clearance prior to entry to the facility. The documentation should include the reason why the exposed individual is not contagious to others. To be considered noncontagious, 1 of the following 4 criteria must be met (see Table 2): (1) the person has a past history of having chickenpox or shingles (diagnosed by a healthcare provider), (2) the person has documentation of 2 doses of varicella-containing vaccine separated by at least 3 months, (3) the person has documented varicella antibodies (also known as a positive varicella IgG blood test), and (4) it has been at least 21 days since the person's last contact with the rash (if the exposed person received postexposure prophylaxis [IVIG or VariZIG], it must be 28 days since the last exposure).

5. Request individuals suspected of having shingles to vacate immediately and refer them for medical evaluation. If the person is diagnosed with shingles (and chickenpox is ruled out), then refer to the above guidance for managing individuals with an active case of shingles.

\section{EN DORSEMENTS}

This guideline has been endorsed by the Pediatric Infectious Diseases Society.

\section{ACKNOWLEDGMENTS}

We thank Erin Rose Alexander for her assistance in the preparation of this document, RMHC for supporting and coordinating an Infection Prevention and Control Stakeholder's Meeting, the SHEA Pediatric Leadership Council, and the following members of the Stakeholder's Group for their contributions to this guideline and their collaboration that made this project possible: Emily Ackiss, MPH, CIC (Oregon Health and Science University, Portland, OR); Zak Boone, MPA (RMHC, Bend, OR); Marybeth Browne, MD (Lurie Children's Hospital, Chicago, IL); Janet Burton (RMHC, Oak Brook, IL); Bryan Gish, MSW (Oregon Health and Science University, Portland, OR); Alan Harris, MD (Rush University Medical Center, Chicago, IL); Derrick Lesnau (RMHC, Austin, TX); Angela Rupp, MT, MS, CIC (Lurie Children's Hospital, Chicago, IL); Robert Schelonka, MD (Oregon Health and Science University, Portland, OR); Jane Scotcher (RMHC, Adelaide, Australia); and Stuart Siegel, MD (Children's Hospital UCLA, Los Angeles, CA).

Potential conflicts of interest. K.A.B. reports a relationship with Calderhead, Lockemeyer \& Peschke, which manufactures products or services used in the treatment of the subjects under discussion. K.A.B. is currently listed or in the past 24 months has been listed as PI or other investigator for the following: Pfizer (multiple studies of Prevnar 13 as well as a phase 2, randomized, activecontrolled, observer-blinded trial to assess the safety, tolerability, and immunogenicity of MCV4, Tdap vaccine, and bivalent rLP2086 vaccine when administered concomitantly in healthy subjects aged 10 to less than 13 years), MedImmune (an observational prospective study to assess respiratory syncytial virus [RSV] respiratory events among premature infants [32-35-week gestational age] -outcomes and risk tracking study [the report study; protocol MIMA213], MedImmune, LLC, 2010), and Novartis (a phase 3, open-label, randomized, multicenter study to evaluate the safety and immunogenicity of ProQuad vaccine when administered concomitantly with Novartis meningococcal ACWY conjugate vaccine to healthy toddlers [protocol V59P21]). K.A.B. reports monies obtained or assigned from Kosair Charities to University of Louisville, receive annual grant to fund fellowship program at more than $\$ 25,000$ as a result of activities. Bryan Gish reports no conflicts of interest relevant to this article. J.A.G.-C. is currently listed or in the past 24 months has been listed as PI or other investigator on GlaxoSmithKline NAI113678funded open-label, multicenter, single-arm study to evaluate the safety and tolerability of intravenous zanamivir in the treatment of hospitalized adult, adolescent, and pediatric subjects with confirmed influenza infection. J.A.G.C. reports monies obtained or assigned by Health Research and Educational Trust (HRET), Oregon State Leader, NCABSI (neonatal CLABSI reduction collaborative) in the amount of more than $\$ 25,000$ as a result of activities. L.K. is currently listed or in the past 24 months has been listed as PI or other investigator to Merck Investigator Studies Program research grant for a $C$. difficile epidemiology and Optimer Pharmaceuticals research support for clinical trial. D.M.Z. is currently listed or in the past 24 months has been listed as PI or other investigator to Chimerix CMX001 and CMV prevention in HSCT recipient. All other authors report no conflicts of interest relevant to this article.

Address correspondence to Judith A. Guzman-Cottrill, DO, Oregon Health and Science University, 707 SW Gaines Road, Mailcode CDRC-P, Portland, OR 97239-3098 (guzmanco@ohsu.edu). 


\section{Family-Centered Residential Facility Guest Health Screening Questions}

Please answer YES or NO to all of the questions below. Have you had any of the following:

YES $\square$ NO $\square \quad$ Fever higher than $100.4^{\circ} \mathrm{F}\left(38.0^{\circ} \mathrm{C}\right)$ in the past 2 days?

YES $\square$ NO $\square \quad$ Vomiting in the past 2 days?

YES $\square$ NO $\square \quad$ Stiff neck or headache with a fever in the past 2 days?

YES $\square$ NO $\square \quad$ Diarrhea in the past 2 days?

YES $\square$ NO $\square \quad$ Current skin lesions that are "weepy" (fluid or pus filled)?

YES $\square$ NO $\square \quad$ ANY current skin rash?

YES $\square$ NO $\square \quad$ Current cold or flu symptoms (runny nose, cough, congestion)?

YES $\square$ NO $\square \quad$ Exposure to Tuberculosis (TB) in the past 2 months?

YES $\square$ NO $\square \quad$ Exposure to any of the following within the past 3 weeks:

$\square$ Chickenpox

$\square$ Household member with head lice

$\square$ Measles

$\square$ Mumps

$\square$ Whooping Cough

Contact the Program Manager to discuss any "yes" answer above, prior to allowing entry

Chickenpox Status:

YES $\square$ NO $\square \quad$ Have you had chickenpox or shingles before?

YES $\square$ NO $\square \quad$ Have you been vaccinated against chickenpox (varicella)?

FIGURE A1. Family-centered residential facility guest health screening questions. 


\section{Family-Centered Residential Facility Medical Clearance Form for Epidemiologically Significant Infections}

This form must be completed by a physician or public health department official who is currently involved in the child's medical care.

Parent/Legal Guardian Name (PRINT)

Pediatric Patient's Name (PRINT)

Pediatric Patient's Diagnosis (please circle):

\begin{tabular}{lll} 
Chickenpox (varicella) & Measles & Tuberculosis \\
E coli colitis/diarrhea/HUS & Mumps & Whooping Cough (pertussis) \\
Hepatitis A & Salmonella colitis/diarrhea & \\
Herpes Infection (HSV-1 or HSV-2) & Shigella colitis/diarrhea & Other \\
\hline
\end{tabular}

I have reviewed this patient's records (named above) and determined the exposed family members NOT contagious to other residential facility guests. Please mark as appropriate below:

Family members have history of complete immunization or natural disease immunity against this specific disease

Family members have completed a full course of appropriate antibiotic exposure prophylaxis against this specific disease

Family members have been evaluated and cleared by public health department

Family members are currently not ill, and not considered a risk since currently healthy

Physician/Public Health Official (PRINT NAME)

Date of Evaluation

Physician/Public Health Official (SIGNATURE)

Physician/Public Health Officer Contact Phone

FIGURE A2. Family-centered residential facility medical clearance form for epidemiologically significant infections. 


\section{APPENDIX B}

\section{VACCINES}

\section{Background}

How vaccines work. Vaccines prime the immune system against future "attacks" by a particular germ or infectious agent (bacteria or virus) that can cause serious disease. The goal is for the vaccine to imitate what happens when the body sees the actual germ but without causing illness. Vaccines may be made from killed bacteria or viruses, weakened (attenuated) viruses, or a substance produced by bacteria (toxin, protein, or polysaccharide antigen). The material in the vaccine is not strong or plentiful enough to make the recipient sick, but it is enough to cause the immune system to produce antibodies. As a result, future immunity is developed against the disease without getting sick. If one is reexposed to the infectious agent, the immune system will recognize and fight it. In some instances, vaccines may provide better immunity than the natural infection.

Impact of vaccines. The development and delivery of vaccines is cited as one of the 10 most important public health accomplishments of the 20th century because of the dramatic prevention of illness, disability, and death from several infections. Examples of the enormous impact that vaccines have had on health in the United States are summarized in Table B1. The numbers of cases of disease and death that have been prevented is extraordinary, and business analyses demonstrate the economic benefit of vaccination. A recent study indicates that vaccinating every child born in the United States prevents approximately 42,000 deaths and 20 million cases of disease. It has been shown with several vaccines that the rate of disease drops dramatically when the vaccine is introduced and, if use is suspended for cost or safety reasons, the disease returns. The reasons why recommended vaccines are provided to all children and adults are summarized in Table B2.

Vaccine safety. Since families no longer encounter diseases such as polio, measles, and bacterial meningitis, they do not appreciate the threat that these diseases pose to children and communities. At the same time, there has been much information in newspapers and on the Internet about potential side effects of vaccines. While some information is accurate, much of it is not, and this may cause unnecessary fear among parents. It is important to understand the dedication of vaccine manufacturers, professional organizations that develop recommendations, and individual providers to assuring the safety of recommended vaccines. There are several stages at which vaccine safety is determined that are summarized in Table B4. Some of the more recent safety questions that have been answered include the following.

1. The potential role of mercury and other chemicals in vaccines in causing autism has been disproven. When this suspicion arose, thimerosal, the mercury-containing preservative in some vaccines, was removed in 1999. However, after many comprehensive studies, it was determined that ethyl mer- cury, the formulation of mercury that was in the preservative, is eliminated from the body rapidly, is not detected in the brain, and certainly does not cause autism. ${ }^{97}$ In contrast, methyl mercury, the form of mercury that is present in the environment (eg, certain fish), is retained in the body. Nevertheless, mercury is not present in currently available vaccines.

2. The role of vaccines themselves in causing autism has also been disproven. Similarly, many studies of autism and vaccines have been completed, and the final determination is that vaccines are NOT the cause of autism. The relevant information is summarized in the May 2004 report of the Institute of Medicine. ${ }^{98}$ This final determination is especially important so that research efforts will be directed toward more likely causes of autism.

3. It was suspected that the first rotavirus vaccine, Rotashield, licensed in 1998, was associated with a rare adverse event, intussusception, where one portion of the intestine slides into another. The recommendation for Rotashield was withdrawn in July 1999, 10 months after licensure, because of concern for this very rare complication ( 1 in 10,000 ). New formulations of rotavirus vaccines were developed and tested in more than 35,000 infants and have been in use since 2006 , with no increased risk of intussusception or other serious adverse events.

4. The belief that influenza vaccine causes the flu is unfounded, since the killed or injectable vaccine is incapable of replication necessary to cause infection and disease. Similarly, the live-attenuated influenza vaccine (Flu-Mist) is unlikely passed from a vaccinated person to an unvaccinated person because it is shed in quantities below the amount required for transmission to others. Furthermore, this vaccine virus cannot cause disease in the lungs because it is "cold adapted," meaning it is unable to replicate at the higher temperatures inside the lungs. It was created to specifically work and remain only inside the nose and throat.

\section{Recommended Vaccine Schedules}

Infants, children, and adolescents. Each year, the CDC, the AAP, and the American Academy of Family Physicians (AAFP) review the new information on vaccines from the previous year and update the recommendations for routine vaccines for children and adolescents for the upcoming year. Changes in vaccine schedules usually include addition of new vaccines that have been licensed for use and changes in numbers of doses of a specific vaccine on the basis of studies of infections that continue to occur, usually due to a waning immunity over time or inadequate primary response. The updated vaccine schedule is published in January or February each year. There are now 16 diseases that are prevented by the vaccines recommended in the schedule for children and adolescents in 2013. Information about these vaccines can be found at the following website: http://www.cdc.gov/vaccines/schedules/easy-to-read /index.html.

Adults. In 2002, the first schedule for immunizations of adults was formulated by the CDC, the AAFP, the American College of Obstetricians and Gynecologists (ACOG), and the 
American College of Physicians-American Society of Internal Medicine (ACP-ASIM) with the IDSA. Since that time, annual updates for the adult immunization schedule according to age and underlying condition are published at the following website: http://www.cdc.gov/vaccines/schedules/easy-to-read /index.html.

The need for immunizations does not end when you reach adulthood. The specific vaccines needed as an adult depend not only on age, lifestyle, overall health, pregnancy status, and travel plans but also on the risk of vaccine-preventable diseases in close contacts. It is important for adults to keep up with the vaccines recommended for them by age and underlying medical condition both for their own health and for reducing the risk of transmission of infection to vulnerable contacts. Healthcare personnel are required to receive certain vaccines according to the recommended schedule to reduce the risk of transmission of infections to vulnerable patients. Also, some vaccines are recommended for adults on the basis of age or risk for serious disease. A discussion of vaccines that are beneficial for each adult should be part of general health maintenance. More information about the recommended adult immunizations is contained in a short video available at http:// www.cdc.gov/CDCTV/VSI_Vaccination/index.html.

\section{Perspective of Family-Centered Residential Facilities}

Guests, such as at a $\mathrm{RMH}$, are frequently (1) children with underlying medical conditions (eg, transplants, malignancy, and prematurity) that place them at increased risk for serious complications of vaccine-preventable diseases, (2) adult and child members of the families of these vulnerable children, and (3) families from foreign countries where there may still be ongoing outbreaks of vaccine-preventable diseases, such as measles. Many of the patients do not respond well to vaccines due to impairment of their immune systems, or they may be too young to receive the recommended vaccines. Therefore, it is critical to minimize their exposure to such vaccine-preventable infections by encouraging that their close contacts have received all of the recommended vaccines. Ideally, all program staff members, volunteers, and families should routinely consult with their healthcare providers to verify their immunization status and obtain the recommended vaccines. By ensuring that staff members and volunteers are up to date on recommended vaccines, the risk of exposure of vulnerable patients and their families to vaccine-preventable illnesses, such as influenza, pertussis (whooping cough), measles, mumps, and varicella (chickenpox), will be reduced. While family-centered residential facilities are not a site of healthcare delivery, the staff members and volunteers can play an important role in providing educational material to families who are far from home, stressed, and not thinking about "routine" health matters. It would be ideal for staff to provide information that reminds residents of the importance of obtaining recommended vaccines and locations where vaccines may be obtained, particularly for influenza during the winter months. This may be developed in partnership with the nearby medical facility where the majority of patients are being treated. Sick children who stay at family-centered residential facilities while receiving medical care should have their immunization records reviewed by their healthcare providers. Their ability to receive vaccines will be determined by their underlying illnesses and therapy. Some vaccines are contraindicated during specific medical therapies.

For prevention of influenza, there is strong evidence that providing vaccine to both adult and pediatric contacts of vulnerable individuals reduces the risk of the vulnerable individuals from developing influenza infection and its complications. ${ }^{99-103}$ Similar observations have been made for the pertussis vaccines, especially the adolescent and adult Tdap formulations, and for pneumococcal vaccines. ${ }^{104,105}$ Herd immunity is especially important for populations of vulnerable patients.

\section{Specific Vaccine-Related Highlights for Family-Centered Residential Facility Staff}

Influenza vaccine. Influenza vaccine is now recommended annually for all individuals who are 6 months of age or older. The benefits of influenza vaccine that have been established include (1) reduced incidence of serious disease, including complications associated with influenza in recipients and in close contacts of recipients; (2) reduced absenteeism from school or work; and (3) reduced use of antimicrobial agents in patients during the flu season. Influenza vaccine does not cause the flu. Influenza vaccination is especially important for the elderly, young children between 6 months and 5 years of age, and those who have high-risk underlying medical conditions, such as pregnancy, diabetes, and neuromuscular, heart, or lung disease. It is also important to vaccinate those who have close contact (household or workplace) with vulnerable patients who are at high risk of developing severe disease and complications, may not respond well to vaccine themselves, or may be too young to receive vaccine. There are 2 types of influenza vaccines: killed vaccine (the shot) and live-attenuated vaccine (the nasal mist). Although the nasal mist may result in shedding of the weakened virus for an average of 7 days, transmission of vaccine virus occurs rarely, and serious illness associated with vaccine strain transmission has not been reported. The nasal mist vaccine may be given to otherwise healthy individuals in contact with immunosuppressed patients except for those who are in the highest-risk phase of their stem cell transplantation, when they are hospitalized in special isolation rooms. Updated information concerning influenza vaccine is published annually by the CDC.

Adult pertussis vaccine (Tdap). Although strides had been made in pertussis (whooping cough) control through vaccinating infants and children under 7 years of age, increasing rates of disease have been noted in the United States since 1990. Increased rates of pertussis have been attributed to waning immunity and a persistent reservoir of disease in adolescents and adults. Infants under 6 months old are too young to have received a complete pertussis vaccination series. There- 
fore, infants are at the highest risk of severe disease and death due to pertussis. In 2006, a new pertussis vaccine containing a lower concentration of pertussis antigens, Tdap, was licensed and is recommended as a single dose for use in adolescents 11 years of age and older. While Tdap provides a booster for protection against tetanus, the importance of Tdap for adults who are in contact with young infants must be emphasized. The most recent recommendations for Tdap vaccine are listed in Table B3.

Measles, mumps, rubella (German measles), varicella (chickenpox). These vaccines are recommended for adults who do not have documentation of vaccination or history of disease. In addition, there is a vaccine, Zostavax, recommended for adults more than or equal to 50 years old to prevent shingles that is caused by a reactivation of the chickenpox virus. Shingles occurs in individuals who have had chickenpox in the past but have waning immunity. Protection against shingles also reduces the risk of a vulnerable patient being exposed to the varicellazoster virus.

Hepatitis A vaccine. Certain areas of the United States and other countries were known to have high rates of hepatitis A virus infections, often due to contaminated water supplies. However, since the introduction of hepatitis A vaccine, the rates of disease have been reduced dramatically. Hepatitis $A$ vaccine is recommended for all children and for adults who are likely to be at risk due to travel or medical conditions, $(\mathrm{eg}$, liver disease of other causes). Individuals likely to come into contact with international adoptees will also benefit from hepatitis $A$ vaccine.

Hepatitis B vaccine. Hepatitis B virus is transmitted through blood or body fluids and may be transmitted sexually. Occupational exposures may occur if there is contact of mucous membranes (conjunctivae, lips) or skin that is not intact with blood or body fluids of infected individuals. Individuals with diabetes are also known to have especially severe disease when they develop hepatitis B infection. Thus, hepatitis B vaccine is recommended for individuals who are sexually active, may come in contact with blood, and who have diabetes.

Pneumococcal vaccines: the "pneumonia" shot, Pneumovax (PPSV 23), and Prevnar (PCV-13). The PPSV 23 vaccine is recommended for individuals over the age of 2 years who have a medical condition that places them at high risk for invasive infection due to Streptococcus pneumoniae. In addition, the vaccine is recommended for all adults over the age of 65 years because of the increased risk of more severe disease in this age group. A different form of pneumococcal vaccine (PCV-7, now PCV-13) has been given routinely to all infants since 2000. In 2012, the recommendation for PCV-13 was extended to all individuals who did not receive this vaccine during infancy and are at increased risk of developing serious disease associated with S. pneumoniae infections related to underlying medical conditions that impair their ability to fight these infections.

TABLE B1. Impact of Vaccines on the Health of Children in the United States ${ }^{108}$

\begin{tabular}{|c|c|c|}
\hline Infection/year vaccine introduced & No. of cases reported each year & No. of deaths reported each year \\
\hline \multicolumn{3}{|l|}{ Smallpox/1798 } \\
\hline $1900-1904$ & 14,164 & 1,528 \\
\hline 1949 & Last case in US & \\
\hline 1971 & Routine vaccination of children ended & \\
\hline 1977 & Eradicated from world & \\
\hline \multicolumn{3}{|l|}{ Measles/1963 } \\
\hline 1920 & 469,924 & 7,575 \\
\hline $1958-1962$ & 503,282 & 432 \\
\hline 2000 & $\begin{array}{c}\text { Measles elimination (interruption of year-round } \\
\text { transmission) achieved in the US }\end{array}$ & \\
\hline 2011 & 222 (all related to importations; $86 \%$ not vaccinated) & \\
\hline \multicolumn{3}{|l|}{ Diphtheria/1923 } \\
\hline 1920 & 147,991 & 13,170 \\
\hline \multicolumn{3}{|l|}{ Pertussis/1940s, 1991, 2006} \\
\hline $1940-1945$ & 175,000 & 5,099 \\
\hline $1980-1990$ & 2,900 & \\
\hline 2010 & 27,550 & 27 \\
\hline \multicolumn{3}{|l|}{ Polio/1955 } \\
\hline $1951-1954$ & 16,316 & 1,879 \\
\hline 1963 & $<100$ & \\
\hline 1991 & $\begin{array}{l}\text { Wild-type viruses eliminated from } \\
\text { Western Hemisphere }\end{array}$ & \\
\hline \multicolumn{3}{|l|}{ H. influenzae type $b^{a} / 1985,1987,1990$} \\
\hline Before 1985 & 20,000, most $<5$ years of age & \\
\hline 2009 & 35 Hib, 178 unknown serotype & \\
\hline \multicolumn{3}{|l|}{ Rotavirus/1998, 2006} \\
\hline Before 1998 & $3,000,000$ & $20-60$ \\
\hline
\end{tabular}

\footnotetext{
a Leading cause of meningitis in children before introduction of vaccine.
} 
TABLE B2. Reasons Why Recommended Vaccines Are Provided to All Children and Adults

1. Immunizations save lives. Just ask your grandparents what it was like to live in an era when the threat of polio returned every summer or when children died from bacterial meningitis.

2. Immunization protects vulnerable close contacts. Very vulnerable babies who are too young to be vaccinated, the elderly, or those with weakened immune systems who may not respond to vaccines can be protected by having all those around them receive vaccines and decrease exposure to serious infections. Examples include pertussis and influenza.

3. Immunizations save time and money.

4. Immunizations will protect future generations.

5. Vaccines are safe and effective. Those who develop, manufacture, and administer vaccines are very interested in assuring the safety of vaccines. Monitoring for safety is ongoing for all vaccines.

TABLE B3. Most Recent Recommendations for Tdap Vaccine ${ }^{106,107}$

\section{Administration of a single dose of Tdap to all those $\geq 11$ years of age.}

a. There is no need to wait a specific amount of time since the previous tetanus shot, $\mathrm{Td}$.

b. All adults can receive Tdap, even if $>65$ years of age.

2. Priority for Tdap includes

a. Contact with young infants, especially newborns.

b. Contact with other vulnerable patients.

c. Pregnant women either during the second or third trimester of each pregnancy or immediately after delivery.

TABLE в 4. Stages of Vaccine Development and Testing in the United States ${ }^{109}$

\section{Vaccine development}

a. Exploratory, preclinical: laboratory research to identify what parts of a microorganism that causes disease could be used in a vaccine to produce immunity, or protection against that disease.

b. Preclinical: use of culture systems and animals in laboratory study to test responses to the candidate vaccine and to identify adjustments that are needed.

c. Application to the Food and Drug Administration (FDA) to obtain permission to test the vaccine in humans.

2. Vaccine testing

a. Phase 1: testing in a small group of healthy adults to determine safety, type of response, and how well the vaccine is tolerated.

b. Phase 2: a larger group that may include children to determine safety, the response produces, the schedule, and method of delivery; includes a test group and a group that receives a placebo or a substance that has no vaccine or medication but is given the same way.

c. Phase 3: a study of a very large number of people in the vaccine and control groups to determine that very rare adverse events do not occur and that the vaccine prevents disease. Recent studies of the rotavirus vaccine contained $>30,000$ people in each group.

3. Approval and licensure by the FDA

a. Review of all safety and efficacy data.

b. Review of the manufacturing process and the site where vaccine is made.

4. Recommendations for use

a. Review of all studies to determine, safety, efficacy, feasibility, schedules, and cost-effectiveness.

b. The Advisory Committee for Immunization Practices (ACIP, Centers for Disease Control and Prevention [CDC]), in conjunction with representatives of the American Academy of Pediatrics (AAP), the American Association of Family Practitioners (AAFP), the Infectious Diseases Society of America (IDSA), and many other stakeholders, summarizes the information available at a public meeting and votes on recommendations.

5. Postmarketing surveillance

a. Once a vaccine has been released and recommended for use, continued monitoring of vaccine safety and efficacy is performed by the vaccine manufacturers and by the CDC through the Vaccine Safety Datalink (VSD) and the Vaccine Adverse Event Reporting System (VAERS), both established in 1990. A parent, a healthcare provider, or friend of the patient who suspects an association between a vaccination and an adverse event may report that event and information about it to VAERS. The CDC then investigates the event and tries to find out whether the adverse event was in fact caused by the vaccination. 


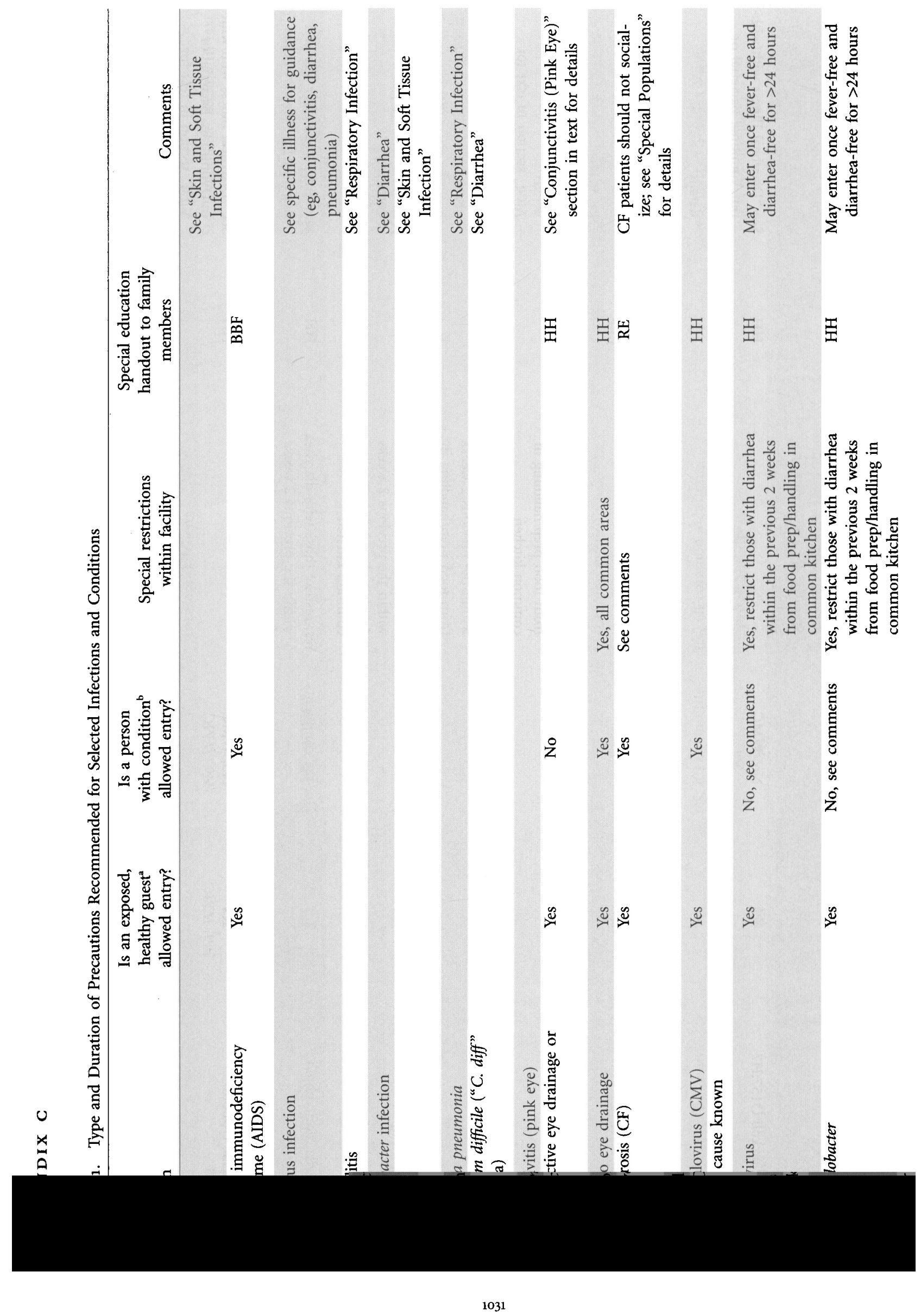




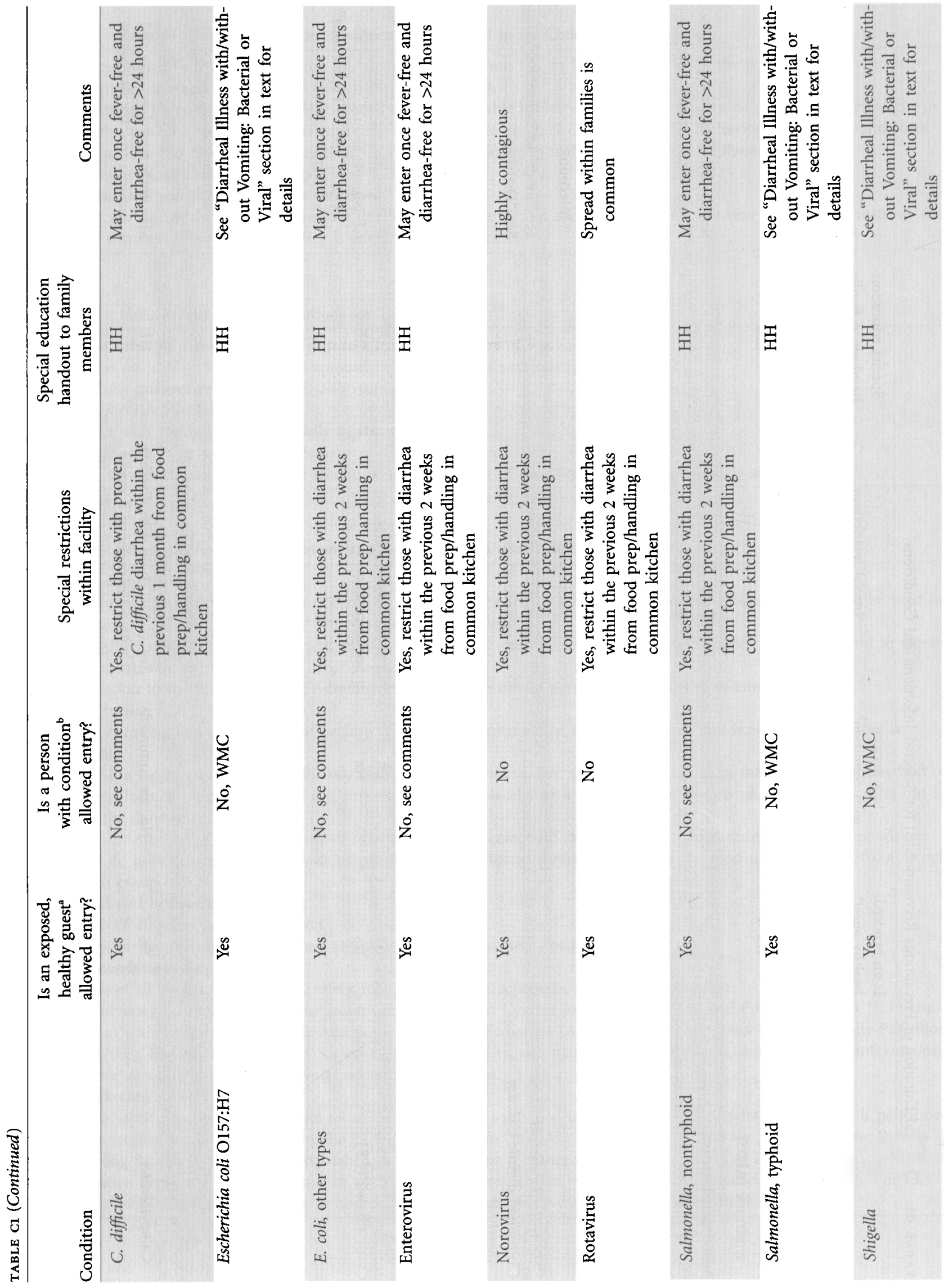




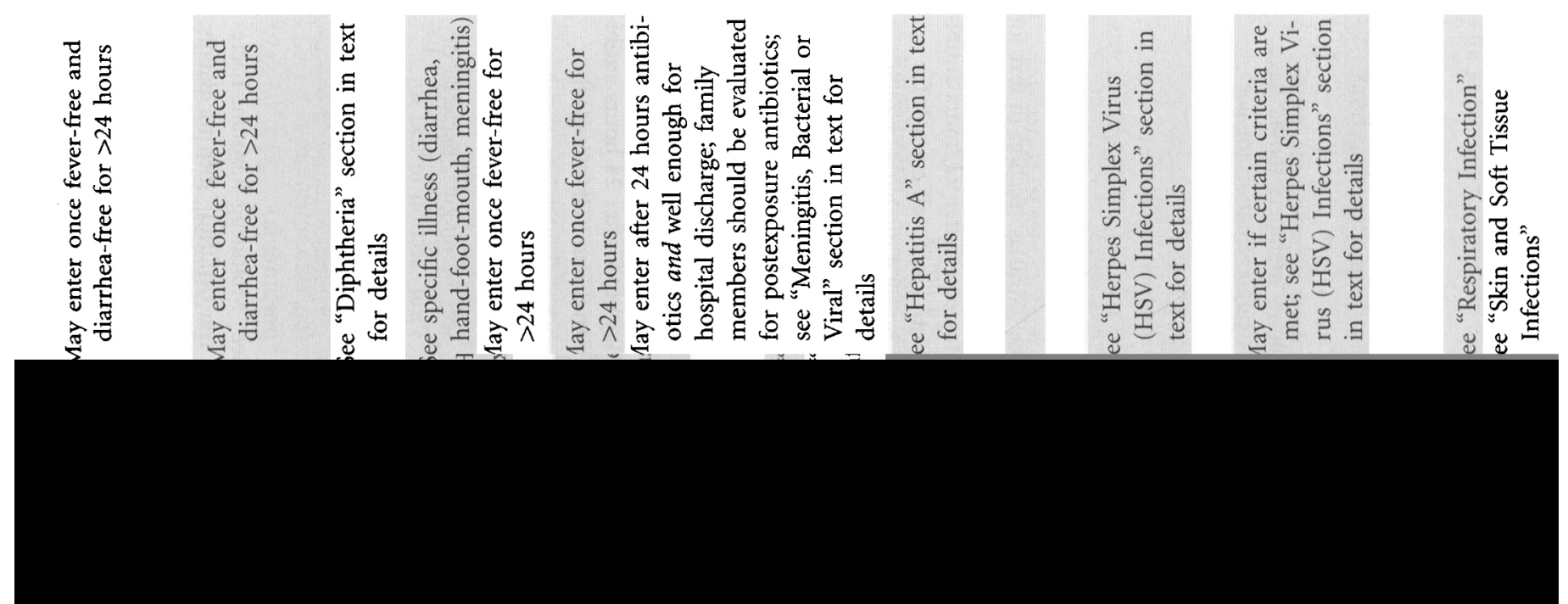

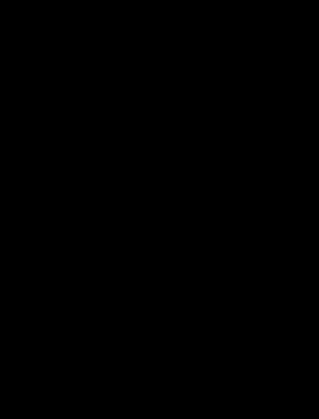

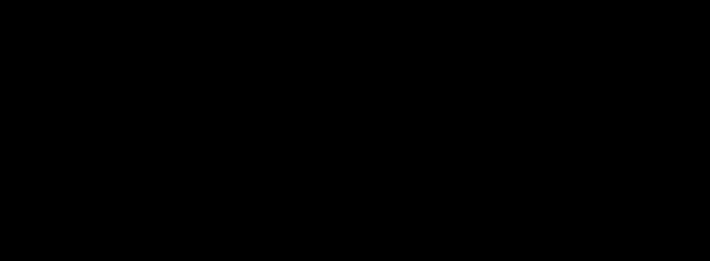

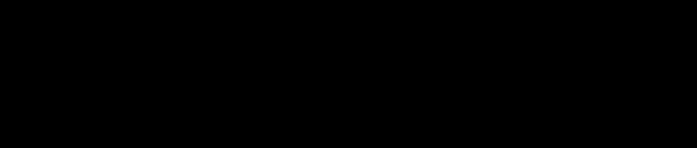

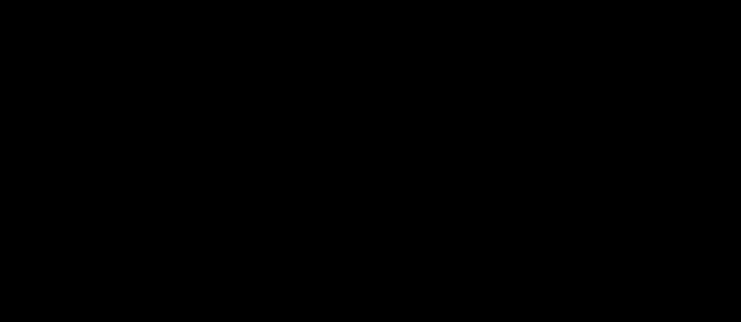

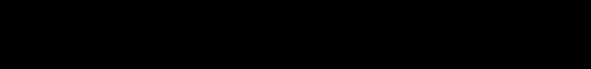

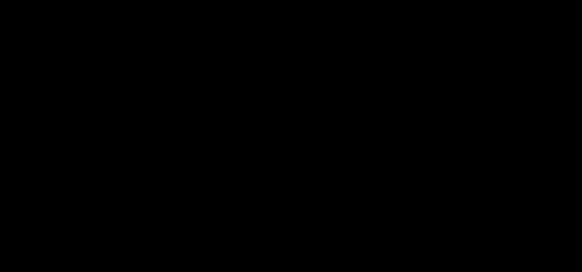

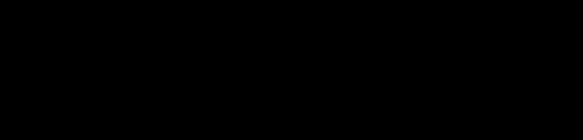

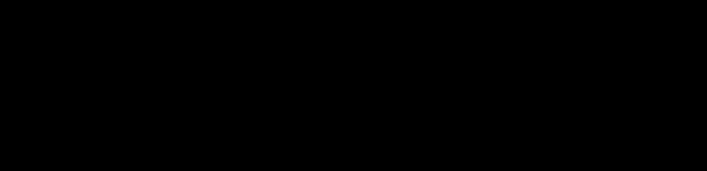




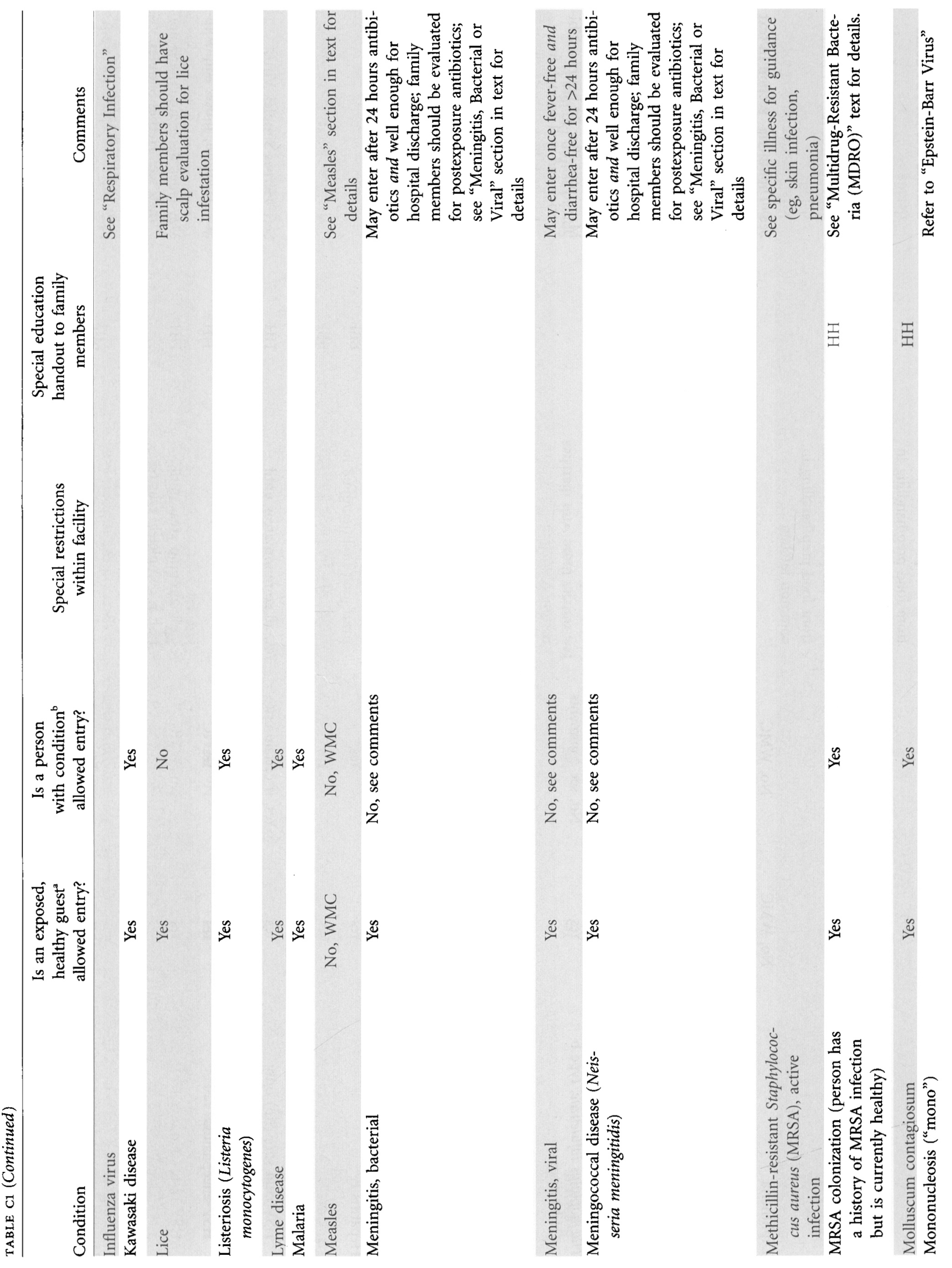




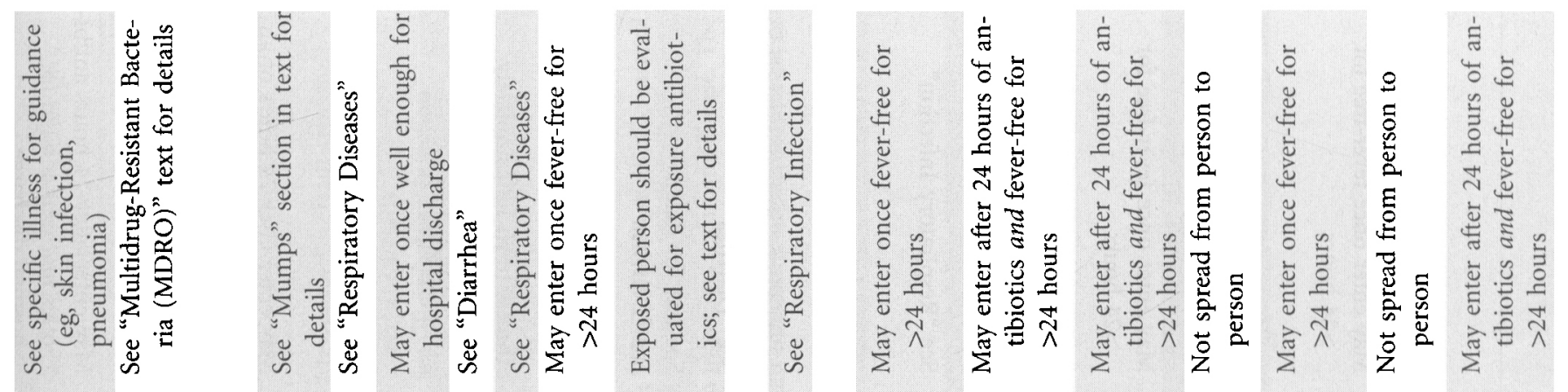

杢

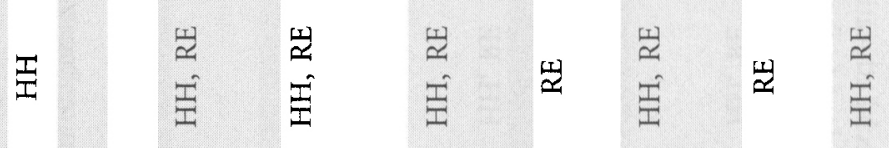

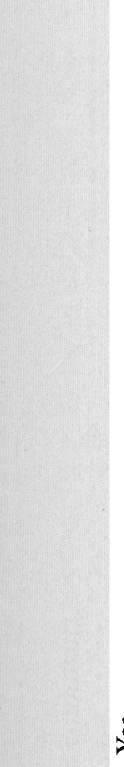

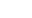

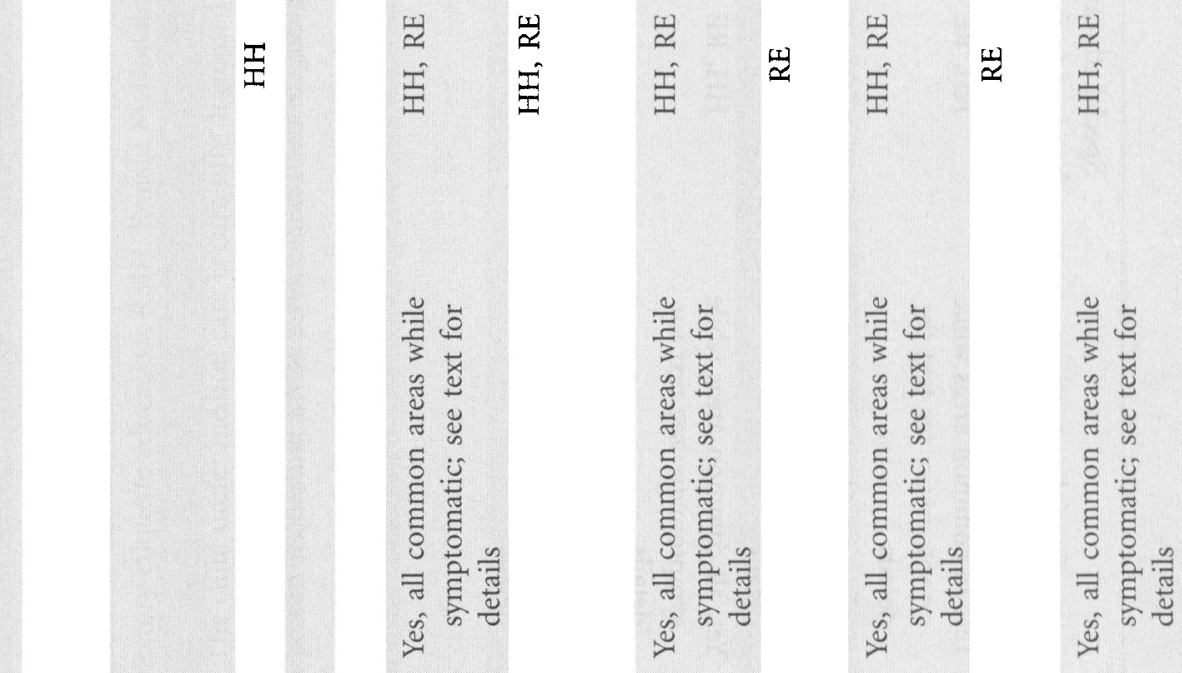

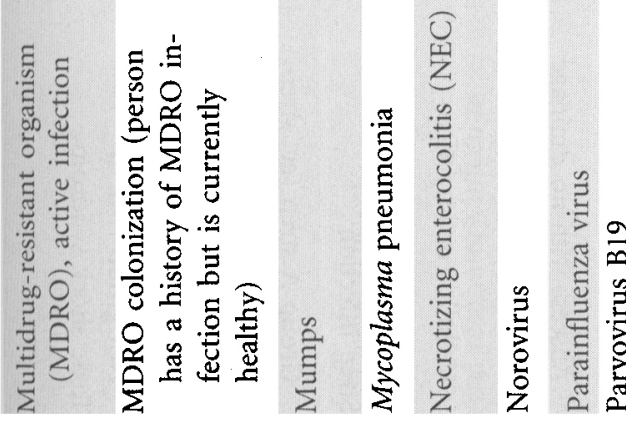

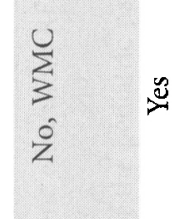

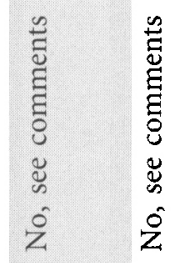

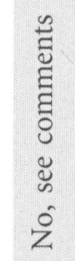

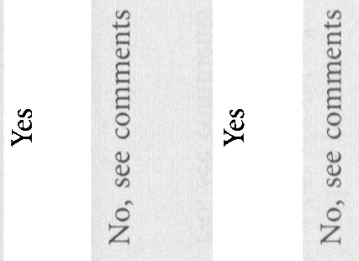

$\approx \quad \sum_{i}^{u} \approx$

ॐ

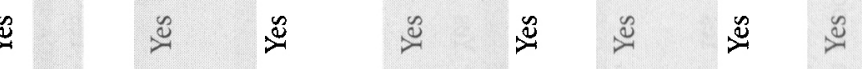

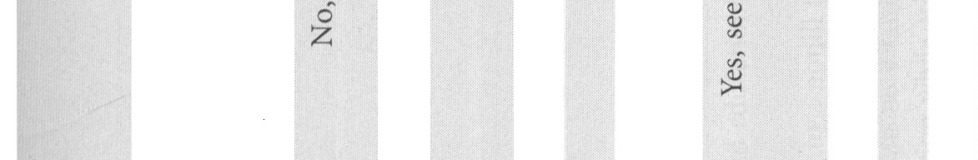




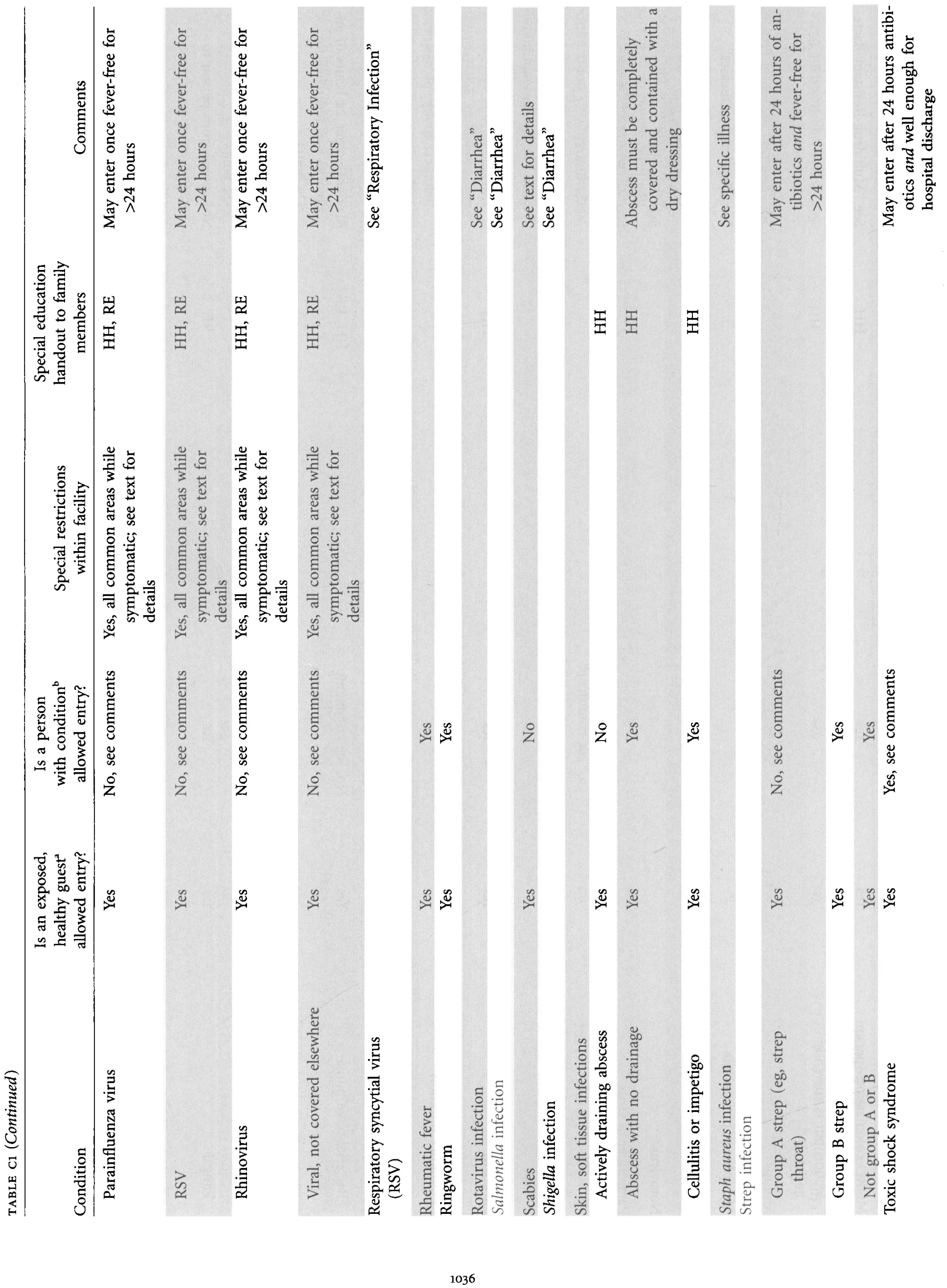




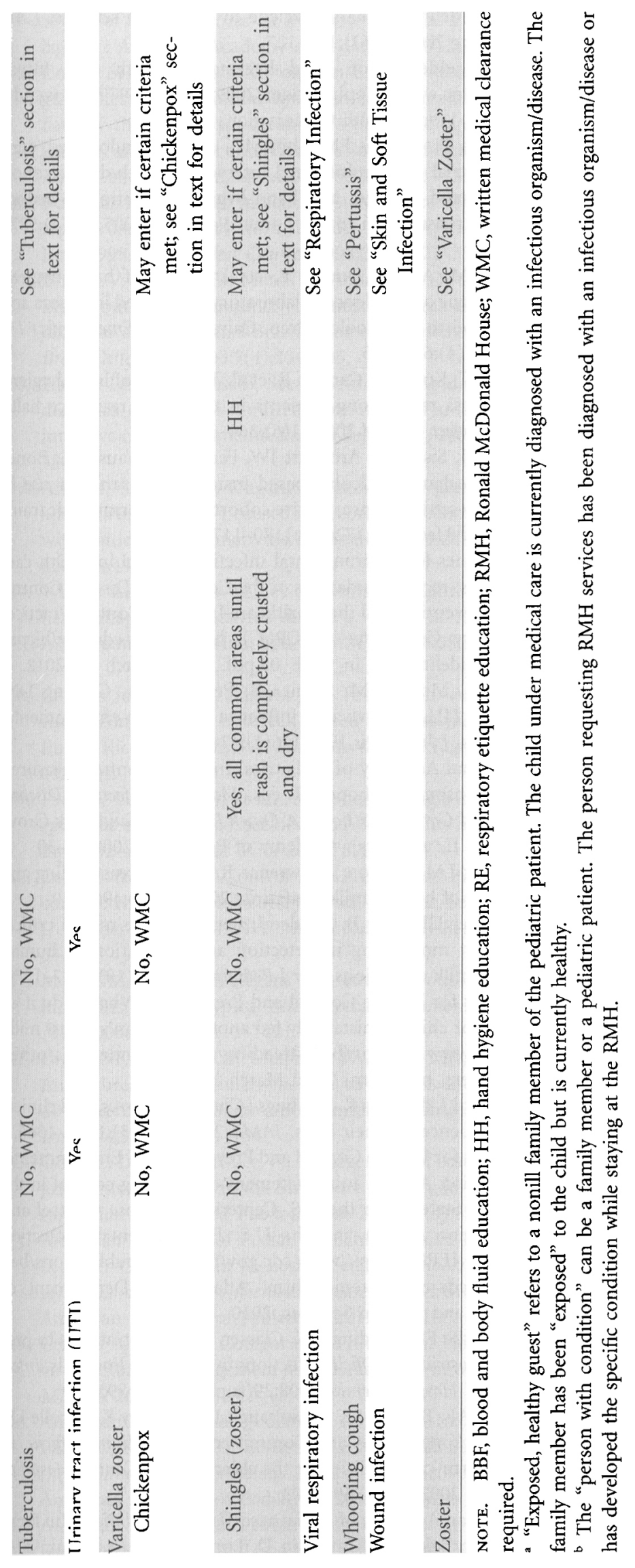




\section{REFERENCES}

1. Guzman-Cottrill JA, Bryant KA, Zerr DM, et al. Infection prevention and control guidance for Ronald McDonald Houses: a needs assessment. Infect Control Hosp Epidemiol 2012;33(3): 299-301.

2. Ronald McDonald House Charities. http://rmhc.org/what-we -do/ronald-mcdonald-house/the-history-of-the-house-that -love-built-2/. Cited March 11, 2012.

3. Adler AL, Casper C, Boeckh M, Heath J, Zerr DM. An outbreak of varicella with likely breakthrough disease in a population of pediatric cancer patients. Infect Control Hosp Epidemiol 2008; 29(9):866-870.

4. Federal Interagency Forum on Child and Family Statistics. http://www.childstats.gov/americaschildren/demo.asp. Cited March 11, 2012.

5. Perrin JM, Bloom SR, Gortmaker SL. The increase of childhood chronic conditions in the United States. JAMA 200727;297(24): 2755-2759.

6. Centers for Disease Control and Prevention. Deaths: final data for 2005. http://www.cdc.gov/nchs/data/nvsr/nvsr56/nvsr56 _10.pdf. Cited March 11, 2012.

7. Ries L, Smith M, Gurney J, et al. Cancer Incidence and Survival among Children and Adolescents: United States SEER Program 1975-1995 [Internet]. 1999th ed. Bethesda, MD: National Cancer Institute, SEER Program. NIH Publication 99-4649.

8. Kulich M, Rosenfeld M, Goss CH, Wilmott R. Improved survival among young patients with cystic fibrosis. J Pediatr 2003; 142(6):631-636.

9. Siegel JD, Rhinehart E, Jackson M, Chiarello L; Health Care Infection Control Practices Advisory Committee. 2007 guideline for isolation precautions: preventing transmission of infectious agents in health care settings. Am J Infect Control 2007; 35(10 suppl 2):S65-S164.

10. Yokoe DS, Mermel LA, Anderson DJ, et al. A compendium of strategies to prevent healthcare-associated infections in acute care hospitals. Infect Control Hosp Epidemiol 2008;29(suppl 1): S12-S21.

11. Recommendations for preventing transmission of infections among chronic hemodialysis patients. MMWR Recomm Rep 2001;50(RR-5):1-43.

12. Saiman L, Siegel J; Cystic Fibrosis Foundation. Infection control recommendations for patients with cystic fibrosis: microbiology, important pathogens, and infection control practices to prevent patient-to-patient transmission. Infect Control Hosp Epidemiol 2003;24(5 suppl):S6-S52.

13. Guide to infection prevention for outpatient settings: minimum expectations for safe care. http://www.cdc.gov/HAI /settings/outpatient/outpatient-care-guidelines.html. Updated July 2011. Atlanta: Centers for Disease Control and Prevention, 2011.

14. Basic infection control and prevention plan for outpatient oncology settings. http://www.cdc.gov/hai/pdfs/guidelines/basic -infection-control-prevention-plan-2011.pdf. Atlanta: Centers for Disease Control and Prevention, 2011.

15. Healthcare Infection Control Practices Advisory Committee and Hand-Hygiene Task Force, Society for Healthcare Epidemiology of America, Association for Professionals in Infection Control and Epidemiology, Infection Diseases Society of Amer- ica. Guideline for hand hygiene in healthcare settings. J Am Coll Surg 2004;198(1):121-127.

16. WHO guidelines on hand hygiene in health care. http:// whqlibdoc.who.int/publications/2009/9789241597906_eng.pdf. Geneva: World Health Organization, 2009.

17. Sandora TJ, Taveras EM, Shih MC, et al. A randomized, controlled trial of a multifaceted intervention including alcoholbased hand sanitizer and hand-hygiene education to reduce illness transmission in the home. Pediatrics 2005;116(3):587594.

18. Talaat $M$, Afifi S, Dueger E, et al. Effects of hand hygiene campaigns on incidence of laboratory-confirmed influenza and absenteeism in schoolchildren, Cairo, Egypt. Emerg Infect Dis 2011;17(4):619-625.

19. White $C$, Kolble R, Carlson $R$, et al. The effect of hand hygiene on illness rate among students in university residence halls. Am J Infect Control 2003;31(6):364-370.

20. Mott PJ, Sisk BW, Arbogast JW, Ferrazzano-Yaussy C, Bondi $\mathrm{CA}$, Sheehan JJ. Alcohol-based instant hand sanitizer use in military settings: a prospective cohort study of army basic trainees. Mil Med 2007;172(11):1170-1176.

21. Guidelines for environmental infection control in health-care facilities: recommendations of the Centers for Disease Control and Prevention and the Healthcare Infection Control Practices Advisory Committee (HICPAC). http://www.cdc.gov/hicpac /pdf/guidelines/eic_in_HCF_03.pdf. Cited March 21, 2012.

22. Bean B, Moore BM, Sterner B, Peterson LR, Gerding DN, Balfour HH Jr. Survival of influenza viruses on environmental surfaces. J Infect Dis 1982;146(1):47-51.

23. American Academy of Pediatrics. Infection control measures. In: Aronson SA, Shope TR, eds. Managing Infectious Diseases in Child Care and Schools: A Quick Reference Guide. Elk Grove Village, IL: American Academy of Pediatrics, 2008:17-30.

24. Gartner LM, Morton J, Lawrence RA, et al. Breastfeeding and the use of human milk. Pediatrics 2005;115(2):496-450.

25. Zeilhofer UB, Frey B, Zandee J, Bernet V. The role of critical incident monitoring in detection and prevention of human breast milk confusions. Eur J Pediatr 2009;168(10):1277-1279.

26. Centers for Disease Control and Prevention. What to do if an infant or child is mistakenly fed another woman's breast milk. http://www.cdc.gov/breastfeeding/recommendations/other _mothers_milk.htm. Cited March 12, 2012.

27. Goddard J, deShazo R. Bed bugs (Cimex lectularius) and clinical consequences of their bites. JAMA 2009;301(13):1358-1366.

28. Centers for Disease Control and Prevention, US Environmental Protection Agency. Joint statement on bed bug control in the United States from the U.S. Centers for Disease Control and Prevention (CDC) and the U.S. Environmental Protection Agency (EPA). http://www.cdc.gov/nceh/ehs/publications/bed _bugs_cdc-epa_statement.htm. Atlanta: US Department of Health and Human Services, 2010.

29. Dubberke ER, Gerding DN, Classen D, et al. Strategies to prevent Clostridium difficile infections in acute care hospitals. Infect Control Hosp Epidemiol 2008;29(suppl 1):S81-S92.

30. Simor AE, Bradley SF, Strausbaugh LJ, Crossley K, Nicolle LE; SHEA Long-Term-Care Committee. Clostridium difficile in long-term-care facilities for the elderly. Infect Control Hosp Epidemiol 2002;23(11):696-703.

31. American Academy of Pediatrics. Clostridium difficile. In: Pickering L, Baker C, Kimberlin D, Long S, eds. Red Book: 2012 
Report of the Committee on Infectious Diseases. Elk Grove Village, IL: American Academy of Pediatrics, 2012:285-287.

32. Cohen SH, Gerding DN, Johnson S, et al. Clinical practice guidelines for Clostridium difficile infection in adults: 2010 update by the Society for Healthcare Epidemiology of America (SHEA) and the Infectious Diseases Society of America (IDSA). Infect Control Hosp Epidemiol 2010;31(5):431-455.

33. National Nosocomial Infections Surveillance (NNIS) system report, data summary from October 1986-April 1998, issued June 1998. Am I Infect Control 1998;26(5):522-533.

34. Brito DV, Oliveira EJ, Matos C, Abdallah VO, Gontijo Filho PP. An outbreak of conjunctivitis caused by multiresistant Pseudomonas aeruginosa in a Brazilian newborn intensive care unit. Braz J Infect Dis 2003;7(4):234-235.

35. Haas J, Larson E, Ross B, See B, Saiman L. Epidemiology and diagnosis of hospital-acquired conjunctivitis among neonatal intensive care unit patients. Pediatr Infect Dis J2005;24(7):586589.

36. Ariga T, Shimada $\mathrm{Y}$, Ohgami $\mathrm{K}$, et al. New genome type of adenovirus serotype 4 caused nosocomial infections associated with epidemic conjunctivitis in Japan. J Clin Microbiol 2004; 42(8):3644-3648.

37. Wu D, Ke CW, Mo YL, et al. Multiple outbreaks of acute hemorrhagic conjunctivitis due to a variant of coxsackievirus A24: Guangdong, China, 2007. J Med Virol 2008;80(10):17621768.

38. Centers for Disease Control and Prevention. Acute hemorrhagic conjunctivitis outbreak caused by coxsackievirus A24Puerto Rico, 2003. MMWR Morb Mortal Wkly Rep 2004;53(28): 632-634.

39. Park K, Lee K, Lee J, et al. Acute hemorrhagic conjunctivitis epidemic caused by coxsackievirus A24 variants in Korea during 2002-2003. J Med Virol 2006;78(1):91-97.

40. Centers for Disease Control and Prevention. Pneumococcal conjunctivitis at an elementary school-Maine, September 20December 6, 2002. MMWR Morb Mortal Wkly Rep 2003;52(4): 64-66.

41. Martin M, Turco JH, Zegans ME, et al. An outbreak of conjunctivitis due to atypical Streptococcus pneumoniae. $N$ Engl J Med 2003;348(12):1112-1121.

42. Crum NF, Barrozo CP, Chapman FA, Ryan MA, Russell KL. An outbreak of conjunctivitis due to a novel unencapsulated Streptococcus pneumoniae among military trainees. Clin Infect Dis 2004;39(8):1148-1154.

43. Ong AE, Dashraath P, Lee VJ. Management of enteroviral conjunctivitis outbreaks in the Singapore military in 2005. Southeast Asian J Trop Med Public Health 2008;39(3):398-403.

44. American Academy of Pediatrics. School health. In: Pickering L, Baker C, Kimberlin D, Long S, eds. Red Book: 2012 Report of the Committee on Infectious Diseases. Elk Grove Village, IL: American Academy of Pediatrics, 2012:152-160.

45. Centers for Disease Control and Prevention. Updated norovirus outbreak management and disease prevention guidelines. MMWR 2011;60(RR-3):1-12.

46. American Academy of Pediatrics. Rotavirus. In: Pickering L, Baker C, Kimberlin D, Long S, eds. Red Book: 2012 Report of the Committee on Infectious Diseases. Elk Grove Village, IL: American Academy of Pediatrics, 2012:626-629.

47. American Academy of Pediatrics. Diphtheria. In: Pickering L, Baker C, Kimberlin D, Long S, eds. Red Book: 2012 Report of the Committee on Infectious Diseases. Elk Grove Village, IL: American Academy of Pediatrics, 2012:307-311.

48. American Academy of Pediatrics. Hepatitis A. In: Pickering $L$, Baker C, Kimberlin D, Long S, eds. Red Book: 2012 Report of the Committee on Infectious Diseases. Elk Grove Village, IL: American Academy of Pediatrics, 2012:361-369.

49. American Academy of Pediatrics. Hepatitis B. In: Pickering L, Baker C, Kimberlin D, Long S, eds. Red Book: 2012 Report of the Committee on Infectious Diseases. Elk Grove Village, IL: American Academy of Pediatrics, 2012:369-390.

50. Weinbaum CM, Williams I, Mast EE, et al; Centers for Disease Control and Prevention. Recommendations for identification and public health management of persons with chronic hepatitis B virus infection. MMWR Recomm Rep 2008;57(RR-8): $1-20$.

51. American Academy of Pediatrics. Hepatitis C. In: Pickering L, Baker C, Kimberlin D, Long S, eds. Red Book: 2012 Report of the Committee on Infectious Diseases. Elk Grove Village, IL: American Academy of Pediatrics, 2012:391-395.

52. Hepatitis $C$ virus infection. American Academy of Pediatrics. Committee on infectious diseases. Pediatrics 1998;101(3 pt 1): 481-485.

53. American Academy of Pediatrics. Human immunodeficiency virus infection. In: Pickering L, Baker C, Kimberlin D, Long S, eds. Red Book: 2012 Report of the Committee on Infectious Diseases. Elk Grove Village, IL: American Academy of Pediatrics, 2012:418-439.

54. American Academy of Pediatrics Task Force on Pediatric AIDS. Pediatric guidelines for infection control of human immunodeficiency virus (acquired immunodeficiency virus) in hospitals, medical offices, schools, and other settings. Pediatrics 1988;82(5):801-807.

55. American Academy of Pediatrics. Herpes simplex. In: Pickering L, Baker C, Kimberlin D, Long S, eds. Red Book: 2012 Report of the Committee on Infectious Diseases. Elk Grove Village, IL: American Academy of Pediatrics, 2012:398-408.

56. American Academy of Pediatrics. Pediculosis capitis (head lice). In: Pickering L, Baker C, Kimberlin D, Long S, eds. Red Book: 2012 Report of the Committee on Infectious Diseases. Elk Grove Village, IL: American Academy of Pediatrics, 2012:543-546.

57. Frankowski BL, Bocchini JA Jr; Council on School Health and Committee on Infectious Diseases. Head lice. Pediatrics 2010; 126(2):392-403.

58. American Academy of Pediatrics. Measles. In: Pickering L, Baker C, Kimberlin D, Long S, eds. Red Book: 2012 Report of the Committee on Infectious Diseases. Elk Grove Village, IL: American Academy of Pediatrics, 2012:489-499.

59. American Academy of Pediatrics. Haemophilus influenza infections. In: Pickering L, Baker C, Kimberlin D, Long S, eds. Red Book: 2012 Report of the Committee on Infectious Diseases. Elk Grove Village, IL: American Academy of Pediatrics, 2012: 345-352.

60. American Academy of Pediatrics. Meningococcal infections. In: Pickering L, Baker C, Kimberlin D, Long S, eds. Red Book: 2012 Report of the Committee on Infectious Diseases. Elk Grove Village, IL: American Academy of Pediatrics, 2012:500-509.

61. American Academy of Pediatrics. Enterovirus (nonpoliovirus) infections. In: Pickering L, Baker C, Kimberlin D, Long S, eds. Red Book: 2012 Report of the Committee on Infectious Diseases. 
Elk Grove Village, IL: American Academy of Pediatrics, 2012: 315-318.

62. Fritz SA, Krauss MJ, Epplin EK, et al. The natural history of contemporary Staphylococcus aureus nasal colonization in community children. Pediatr Infect Dis J 2011;30(4):349-351.

63. Lacey S, Flaxman D, Scales J, Wilson A. The usefulness of masks in preventing transient carriage of epidemic methicillin-resistant Staphylococcus aureus by healthcare workers. J Hosp Infect 2001;48(4):308-311.

64. Gray JW, George RH. Experience of vancomycin-resistant enterococci in a children's hospital. J Hosp Infect 2000;45(1):1118.

65. Tsiatis AC, Manes B, Calder C, Billheimer D, Wilkerson KS, Frangoul $\mathrm{H}$. Incidence and clinical complications of vancomycin-resistant enterococcus in pediatric stem cell transplant patients. Bone Marrow Transplant 2004;33(9):937-941.

66. American Academy of Pediatrics. Mumps. In: Pickering L, Baker C, Kimberlin D, Long S, eds. Red Book: 2012 Report of the Committee on Infectious Diseases. Elk Grove Village, IL: American Academy of Pediatrics, 2012:514-518.

67. Jenkinson D. Duration of effectiveness of pertussis vaccine: evidence from a 10 year community study. $\mathrm{Br} \mathrm{Med} J$ (Clin Res Ed) $1988 ; 296(6622): 612-614$.

68. Cherry JD. Epidemiological, clinical, and laboratory aspects of pertussis in adults. Clin Infect Dis 1999;28(suppl 2):S112-S117.

69. Bryant KA, Humbaugh $K$, Brothers $K$, et al. Measures to control an outbreak of pertussis in a neonatal intermediate care nursery after exposure to a healthcare worker. Infect Control Hosp Epidemiol 2006;27(6):541-545.

70. Khetsuriani N, Bisgard K, Prevots DR, et al. Pertussis outbreak in an elementary school with high vaccination coverage. Pediatr Infect Dis $J$ 2001;20(12):1108-1112.

71. Srugo I, Benilevi D, Madeb R, et al. Pertussis infection in fully vaccinated children in day-care centers, Israel. Emerg Infect Dis 2000;6(5):526-529.

72. Fisher MC, Long SS, McGowan KL, Kaselis E, Smith DG. Outbreak of pertussis in a residential facility for handicapped people. J Pediatr 1989;114(6):934-939.

73. Yeh J, Batt RE. Contingency plans and the sniffles. Acad Med 2006;81(4):325.

74. Guidelines for the control of pertussis outbreaks. http:// www.cdc.gov/vaccines/pubs/pertussis-guide/guide.htm. Atlanta: Centers for Disease Control and Prevention, 2000.

75. Bisgard KM, Pascual FB, Ehresmann KR, et al. Infant pertussis: who was the source? Pediatr Infect Dis J 2004;23(11):985-989.

76. Kretsinger $\mathrm{K}$, Broder $\mathrm{KR}$, Cortese MM, et al. Preventing tetanus, diphtheria, and pertussis among adults: use of tetanus toxoid, reduced diphtheria toxoid and acellular pertussis vaccine recommendations of the Advisory Committee on Immunization Practices (ACIP) and recommendation of ACIP, supported by the Healthcare Infection Control Practices Advisory Committee (HICPAC), for use of tdap among healthcare personnel. MMWR Recomm Rep 2006;55(RR-17):1-37.

77. Hall $C B$, Weinberg GA, Iwane $M K$, et al. The burden of respiratory syncytial virus infection in young children. $N$ Engl J Med 2009;360(6):588-589.

78. Nichols WG, Gooley T, Boeckh M. Community-acquired respiratory syncytial virus and parainfluenza virus infections after hematopoietic stem cell transplantation: the Fred Hutchinson
Cancer Research Center experience. Biol Blood Marrow Transplant 2001;7(suppl):11S-15S.

79. Harrington RD, Hooton TM, Hackman RC, et al. An outbreak of respiratory syncytial virus in a bone marrow transplant center. I Infect Dis 1992;165(6):987-993.

80. American Academy of Pediatrics. Scabies. In: Pickering L, Baker C, Kimberlin D, Long S, eds. Red Book: 2012 Report of the Committee on Infectious Diseases. Elk Grove Village, IL: American Academy of Pediatrics, 2012:641-643.

81. Obasanjo OO, Wu P, Conlon M, et al. An outbreak of scabies in a teaching hospital: lessons learned. Infect Control Hosp Epidemiol 2001;22(1):13-18.

82. Andersen BM, Haugen $H$, Rasch $M$, Heldal Haugen A, Tageson A. Outbreak of scabies in Norwegian nursing homes and home care patients: control and prevention. J Hosp Infect 2000;45(2): 160-164.

83. Centers for Disease Control and Prevention. Parasites—scabies: institutional settings. http://www.cdc.gov/parasites/scabies /health_professionals/institutions.html. Cited March 15, 2012. Accessed January 8, 2013.

84. Stevens DL, Bisno AL, Chambers HF, et al. Practice guidelines for the diagnosis and management of skin and soft-tissue infections. Clin Infect Dis 2005;41(10):1373-1406.

85. Association for Professionals in Infection Control and Epidemiology. Guide to the elimination of methicillin-resistant Staphylococcus aureus (MRSA) transmission in hospital settings. 2nd ed. 2010. http://www.apic.org/Resource_/Elimination GuideForm/631fcd91-8773-4067-9f85-ab2a5b157eab/File /MRSA-elimination-guide-2010.pdf. Accessed January 8 , 2013.

86. Association for Professionals in Infection Control and Epidemiology. Guide to the elimination of methicillin-resistant Staphylococcus aureus (MRSA) in the long-term care facility. 2009. http://www.apic.org/Resource_/EliminationGuideForm 108b 12595-9f92-4a64-ad41-4afdd0088224/File/APIC-MRSA -in-Long-Term-Care.pdf. Accessed January 8, 2013.

87. Calfee DP, Salgado CD, Classen D, et al. Strategies to prevent transmission of methicillin-resistant Staphylococcus aureus in acute care hospitals. Infect Control Hosp Epidemiol 2008; 29(suppl 1):\$62-\$80.

88. American Academy of Pediatrics. Group A streptococcal infections. In: Pickering L, Baker C, Kimberlin D, Long S, eds. Red Book: 2012 Report of the Committee on Infectious Diseases. Elk Grove Village, IL: American Academy of Pediatrics, 2012: 668-680.

89. Jensen PA, Lambert LA, Iademarco MF, Ridzon R; Centers for Disease Control and Prevention. Guidelines for preventing the transmission of Mycobacterium tuberculosis in health-care settings, 2005. MMWR Recomm Rep 2005;54(RR-17):1-141.

90. American Academy of Pediatrics. Tuberculosis. In: Pickering L, Baker C, Kimberlin D, Long S, eds. Red Book: 2012 Report of the Committee on Infectious Diseases. Elk Grove Village, IL: American Academy of Pediatrics, 2012:736-759.

91. American Academy of Pediatrics. Varicella-zoster infections. In: Pickering L, Baker C, Kimberlin D, Long S, eds. Red Book: 2012 Report of the Committee on Infectious Diseases. Elk Grove Village, IL: American Academy of Pediatrics, 2012:774-789.

92. Langley JM, Hanakowski M. Variation in risk for nosocomial chickenpox after inadvertent exposure. I Hosp Infect 2000; 44(3):224-226. 
93. Ross AH. Modification of chicken pox in family contacts by administration of gamma globulin. $N$ Engl J Med 1962;267: 369-376.

94. Saidel-Odes L, Borer A, Riesenberg K, et al. An outbreak of varicella in staff nurses exposed to a patient with localized herpes zoster. Scand I Infect Dis 2010;42(8):620-622.

95. Lopez AS, Burnett-Hartman A, Nambiar R, et al. Transmission of a newly characterized strain of varicella-zoster virus from a patient with herpes zoster in a long-term-care facility, West Virginia, 2004. I Infect Dis 2008;197(5):646-653.

96. Marin M, Guris D, Chaves SS, Schmid S, Seward JF; Advisory Committee on Immunization Practices, Centers for Disease Control and Prevention. Prevention of varicella: recommendations of the Advisory Committee on Immunization Practices (ACIP). MMWR Recomm Rep 2007;56(RR-4):1-40.

97. Price CS, Thompson WW, Goodson B, et al. Prenatal and infant exposure to thimerosal from vaccines and immunoglobulins and risk of autism. Pediatrics 2010;126(4):656-664.

98. Immunization Safety Review Committee. Front matter. Immunization Safety Review: Vaccines and Autism. Washington, DC: National Academies Press, 2004.

99. Talbot TR. Revised SHEA position paper: influenza vaccination of healthcare personnel. Infect Control Hosp Epidemiol 2010; 31:987.

100. Puig-Barbera J. Reduction in hospital admissions for pneumonia in non-institutionalised elderly people as a result of influenza vaccination: a case-control study in Spain. J Epidemiol Community Health 1997;51:526.

101. Reichert TA. The Japanese experience with vaccinating schoolchildren against influenza. N Engl J Med 2001;344:889.

102. Piedra PA. Herd immunity in adults against influenza-related illnesses with use of the trivalent-live attenuated influenza vaccine (CAIV-T) in children. Vaccine 2005;23:1540.

103. Loeb $M$. Effect of influenza vaccination of children on infection rates in Hutterite communities: a randomized trial. JAMA 2010;303:943.

104. Grizas AP, Camenga D, Vázquez M. Cocooning: a concept to protect young children from infectious diseases. Curr Opin Pediatr 2012;24(1):92-97.

105. Lynch JP 3rd, Zhanel GG. Streptococcus pneumoniae: epidemiology and risk factors, evolution of antimicrobial resistance, and impact of vaccines. Curr Opin Pulm Med 2010;16(3):217225.

106. Centers for Disease Control and Prevention. FDA approval of expanded age indication for a tetanus toxoid, reduced diphtheria toxoid, and acellular pertussis vaccine. MMWR 2011; 60(37):1279-1280.

107. Centers for Disease Control and Prevention. Updated recommendations for use of tetanus toxoid, reduced diphtheria toxoid and acellular pertussis vaccine (Tdap) in pregnant women and persons who have or anticipate having close contact with an infant aged $<12$ months-Advisory Committee on Immunization Practices (ACIP), 2011. MMWR 2011; 60(41):1424-1426.

108. Centers for Disease Control and Prevention. Achievements in public health, 1900-1999 impact of vaccines universally recommended for children-United States, 1990-1998. MMWR 1999;48(12):243-248.

109. College of Physicians of Philadelphia. Vaccine development, testing, and regulation-history of vaccines. http://www .historyofvaccines.org/content/articles/vaccine-development -testing-and-regulation. Accessed November 12, 2012. 